\title{
Nanotechnology in Drug Delivery
}

\author{
Martins Ochubiojo Emeje, Ifeoma Chinwude Obidike, \\ Ekaete Ibanga Akpabio and Sabinus Ifianyi Ofoefule
}

Additional information is available at the end of the chapter

http://dx.doi.org/10.5772/51384

\section{Introduction}

Nanoscience has been variously defined at different fora, books, journals and the web, yet one thing is common; it involves the study of the control of matter on an atomic and molecular scale. This molecular level investigation is at a range usually below $100 \mathrm{~nm}$. In simple terms, a nanometer is one billionth of a meter and the properties of materials at this atomic or subatomic level differ significantly from properties of the same materials at larger sizes. Although, the initial properties of nanomaterials studied were for its physical, mechanical, electrical, magnetic, chemical and biological applications, recently, attention has been geared towards its pharmaceutical application, especially in the area of drug delivery.

This is because of the challenges with use of large size materials in drug delivery, some of which include poor bioavailability, in vivo stability, solubility, intestinal absorption, sustained and targeted delivery to site of action, therapeutic effectiveness, generalized side effects, and plasma fluctuations of drugs. Of recent, several researches in nanodrug delivery have been designed to overcome these challenges through the development and fabrication of nanostructures. It has been reported that, nanostructures have the ability to protect drugs from the degradation in the gastrointestinal tract, the technology can allow target delivery of drugs to various areas of the body. The technology enables the delivery of drugs that are poorly water soluble and can provide means of bypassing the liver, thereby preventing the first pass metabolism Nanotechnology increases oral bioavailability of drugs due to their specialized uptake mechanisms such as absorptive endocytosis and are able to remain in the blood circulation for a long time, releasing the incorporated drug in a controlled fashion, leading to less plasma fluctuations and minimized side-effects. Nanoscale size nanostructures are able to penetrate tissues and are easily taken up by cells, allowing for efficient delivery of drugs to target sites of action. Uptake of nanostructures has been reported to be 15-250 times greater than that of microparticles in the 1-10 um range. Nanotechnology improves performance and acceptability of dosage forms by increasing 
their effectiveness, safety, patient adherence, as well as ultimately reducing health care costs. It may also enhance the performance of drugs that are unable to pass clinical trial phases. Nanotechnology definitely promises to serve as drug delivery carrier of choice for the more challenging conventional drugs used for the treatment and management of chronic diseases such as cancer, asthma, hypertension, HIV and diabetes.

\section{Nanotechnology-based drug delivery systems}

\subsection{Smart drug delivery systems}

Ideally, nanoparticulate drug delivery system should selectively accumulate in the required organ or tissue and at the same time, penetrate target cells to deliver the bioactive agent. It has been suggested $(1,2)$ that, organ or tissue accumulation could be achieved by the passive or antibody-mediated active targeting $(3,4)$, while the intracellular delivery could be mediated by certain ligands $(5,6)$ or by cell-penetrating peptides $(7,8)$. Thus, a drug delivery system (DDS) should be multifunctional and possess the ability to switch on and switch off certain functions when necessary. Another important requirement is that different properties of the multifunctional DDS are coordinated in an optimal fashion. Thus, for example, if the system is to be constructed that can provide the combination of the longevity allowing for the target accumulation and specific cell surface binding allowing, two requirements must be met; the half-life of the carrier in the circulation should be long enough and second, the internalization of the DDS by the target cells should proceed fast enough not to allow for the carrier degradation and drug loss in the interstitial space. Intracellular transport of bioactive molecules is one of the key problems in drug delivery. Nanoparticulate DDS, such as liposomes and micelles, are frequently used to increase the efficacy of drug and DNA delivery and targeting $(9,10)$. So far, very few successful attempts have been made to deliver various drug carriers directly into the cell cytoplasm, bypassing the endocytic pathway, to protect drugs and DNA from the lysosomal degradation, thus enhancing drug efficiency and DNA incorporation into the cell genome (11-14). Within the multifunctional DDS, it has been postulated that, the development of a DDS built in such a way that during the first phase of delivery, a nonspecific cell-penetrating function is shielded by the organ/tissue-specific delivery will be possible. Upon accumulating in the target, protecting polymer or antibody attached to the surface of the DDS via the stimulisensitive bond should detach under the action of local pathological conditions such as abnormal $\mathrm{pH}$ or temperature and expose the previously hidden second function allowing for the subsequent delivery of the carrier and its cargo inside cells. While such DDS should be stable in the blood for a long time to allow for an efficient target accumulation, it has to lose the protective coat inside the target almost instantly to allow for fast internalization thereby minimizing the washing away of the released drug or DNA. Intracellular trafficking, distribution, and fate of the carrier and its cargo can be additionally controlled by its charge and composition, which can drive it to the nuclear compartment or toward other cell organelles.

It has been reported within the past few years, that certain proteins and peptides (such as TAT peptide) can enter cell cytoplasm directly and even target cell nuclei $(15,16)$. Certain 
proteins and peptides have also been used for the intracellular delivery of small drug molecules, large molecules (enzymes, DNA), and nanoparticulates (quantum dots, iron oxide nanoparticles, liposomes) $(13,17-22)$. The mechanism of this phenomenon is currently a subject of investigation, although important progress has been made, as some reports show that electrostatic interactions and hydrogen bonding lay behind certain proteins and peptides-mediated direct transduction of small molecules $(23,24)$, while the energydependent macropinocytosis is responsible for certain proteins and peptides-mediated intracellular delivery of large molecules and nanoparticulates with their subsequent enhanced release from endosomes into the cell cytoplasm $(25-28)$.

One of the most outstanding achievements in the drug delivery field was the development of smart drug delivery systems (SDDSs), also called stimuli-sensitive delivery systems. The concept is based on rapid transitions of a physicochemical property of polymer systems upon a stimulus. This stimulus includes physical (temperature, mechanical stress, ultrasound, electricity, light), chemical $(\mathrm{pH}$, ionic strength), or biological (enzymes, biomolecules) signals and such stimuli can either be internal, resulting from changes in the physiological condition of a living subject, or "external" signals, artificially induced to provoke desired events. SDDS provides a programmable and predictable drug release profile in response to various stimulation sources. Fig 1 below shows a typical smart drug delivery system;

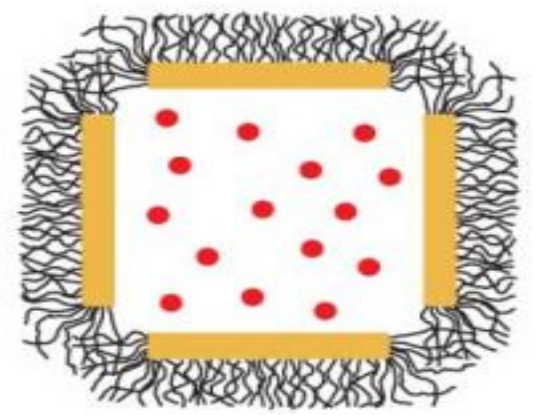

Figure 1. Smart drug delivery system -- Gold nanocage covered with polymer

Depending on the desired applications, one may design different drug delivery systems for enhanced therapeutic efficiency with low systemic toxicity and side effects. SDDS has several advantages compared to conventional drug delivery systems. The conventional controlled release systems are based on the predetermined drug release rate irrespective of the environmental condition at the time of application. On the other hand, SDDS is based on the release-on-demand strategy, allowing a drug carrier to liberate a therapeutic drug only when it is required in response to a specific stimulation. The best example of SDDS has been self-regulated insulin delivery systems that can respond to changes in the environmental glucose level $(29,30)$. One of the most widely used SDDSs has been polymeric micelles. Many polymeric micelles consisting of hydrophobic and hydrophilic polymer blocks have been developed. They have been found to dissolve water-insoluble drugs, such as 
doxorubicin or paclitaxel, at high concentrations. When administered to the body, drug release from polymeric micelles usually depends on simple diffusion, degradation of the micelle blocks, or disruption of the micelles by body components.

The release kinetics of the loaded drug can be modulated by varying the degradation rate of hydrophobic polymer blocks, but because the degradation rate is usually very slow, the loaded drug is released by diffusion from polymeric micelles. This slow release by passive diffusion may not be desirable, as the polymeric micelles reaching the target site need to release their contents fast. To solve this problem, smart polymeric micelles have been designed to liberate the loaded therapeutic agent at the targeted site fast. For example, Lee et al, (31) reported that Poly (ethylene glycol)-b-polyhistidine (PEG-b-PHis) forms micelles only over the $\mathrm{pKb}$ of the polyhistidine block ( $\mathrm{pH}$ 6.5-7.0). It is interesting to know that, the $\mathrm{pKb}$ can be adjusted by varying the molecular weight of polyhistidine. Since solid tumors have a slightly acidic environment, a small reduction in $\mathrm{pH}$ to less than 7 at the tumor site triggers dissociation of the polymeric micelle to release its contents. In a separate study, Lee et al (32) reported that, PEG-b- polyhistidine micelles containing doxorubicin effectively killed multi-drug resistant MCF-7 cells at pH 6.8. Similarly, Hruby et al, (33) reported that, SDDS can achieve a highly localized drug accumulation at target sites even though it is administered parenterally. It is therefore postulated that, SDDS with enhanced targeting property is highly promising in increasing the efficiency and efficacy of therapy while at the same time minimizing side effects.

\subsection{Polymer-drug conjugates}

Polymer-drug conjugates are a class of polymer therapeutics that consists of a water-soluble polymer that is chemically conjugated to a drug through a biodegradable linker. The idea started in 1975 when Ringsdorf proposed the use of polymer-drug conjugates to deliver hydrophobic small molecules (34). The reasoning was that, small molecule drugs, especially hydrophobic compounds, have a low aqueous solubility and a broad tissue distribution profile such that, administration of the free drug may result in serious side effects. Therefore, conjugation of these compounds to hydrophilic, biocompatible polymers would significantly increase their aqueous solubility, modify their tissue distribution profile and enhance their plasma circulation half-life. An important attribute of colloidal systems is their hydrodynamic diameter, which are typically about 3-20 nm for polymer-drug conjugates (35) and between 10 and $200 \mathrm{~nm}$ for colloidal particles such as micelles or liposomes. The colloidal nature or size of these vehicles can facilitate their retention within the circulation for prolonged periods, in comparison to low molecular weight small molecules. One major difference between polymer-drug conjugates and delivery systems that contain physically entrapped drug (e.g., micelles and liposomes) is that the drug is chemically conjugated to the polymer and therefore these systems qualify as new chemical entities (NCE). Classification as an NCE is often accompanied by additional development and regulatory hurdles that must be met in order to receive approval. Over the last decade, polymerconjugate technology has proven to be a viable formulation strategy. There have been reports $(36-38)$ of bioconjugation of protein and peptide to PEG been able to significantly 
improve the efficacy of these macro- molecular drugs by increasing their stability in the presence of proteases and decreasing their immunogenicity. Studies have also shown that by using PEG in a specific molecular weight range, the fast renal clearance and mononuclear phagocytic system uptake of the drugs can be prevented or delayed leading to a prolonged plasma half-life for the conjugated molecules. Successful applications have led to several FDA- approved products e.g. Neulasta ${ }^{\circledR}$. The first practical use of polymer therapeutics that resulted in an FDA-approved anti-cancer treatment was the introduction of PEG-Lasparaginase (Oncaspar1) in 1994. This conjugate is composed of PEG polymer (MW $5 \mathrm{kD})$ attached to the enzyme, L-asparaginase, and is used for the treatment of acute lymphoblastic leukemia (39). In fact, polymer-drug conjugate itself can be considered as a nanovehicle. Various conjugates have been developed and clinically tested. Recent advances in polymer-drug conjugates are well described in reviews (Duncan, 2006; Duncan, Vicent, Greco, \& Nicholson, 2005). One of the major advantages of polymer-drug conjugates is prolonged circulation in the blood stream by retarding degradation/metabolism/excretion rates of the conjugated drugs. Many peptide and protein drugs cannot be delivered by oral administration because of their large molecular weights. Even when administered directly into the blood stream, they do not remain in the blood for a long time due to fast degradation and metabolism, limiting the clinical applications. The circulation times of these drugs have increased substantially by conjugation with polymers, such as PEG. A good example is the glucagon-like peptide-1, which regulates food uptake and insulin release. The peptide is a very useful therapeutic agent for diabetic patients, but it is liable to degradation by a plasma enzyme, dipeptidyl dipeptidase IV, but by introducing one PEG chain, Lee et al (40) showed that its half-life could be increased up to 40 folds over the natural form. Very often, low molecular weight drugs with high hydrophobicity are used for conjugation with attendant reduction in the degradation/clearance rate as well as the toxicity of the conjugated drug. The therapeutic effect is achieved upon hydrolysis inside the target cells to release the original drug. The polymers used in conjugation usually have stimuli-responsiveness, imparting unique properties into the conjugated drug such that, its activities can be turned on or off by external signals. For example, Shimoboji et al, $(41,42)$ reported that, the catalytic activity endoglucanase 12A upon conjugation could be turned on by application of UV light or high temperature because, it was conjugated with either photosensitive or thermo-sensitive polymers. The active site of the enzyme was exposed by collapsing the conjugated long polymer chain by external stimuli. Once visible light was turned on or the temperature was lowered, the enzyme activity vanished due to the blocking of the active site by the extended polymer chain. $(43,44)$

\subsection{Multifunctional drug carriers}

A multifunctional drug delivery system (MDDS) refers to drug carrier that has multiple properties of prolonged blood circulation, passive or active localization at specific disease site, stimuli-sensitivity, ability to deliver drug into intracellular target organelles, and/or imaging ability (45). Technically therefore, it has two or more functions, infact, SDDS and polymer-drug conjugates discussed above can be considered MDDS. In addition to 
delivering drugs, MDDS can carry out the second function, such as stimuli-responsiveness or hydrolysis inside cells. Some reported MDDS include the biotin-tagged $\mathrm{pH}$-sensitive polymeric micelles based on a mixture of PLA-b-PEG-b-PHis-biotin (PLA=poly (L-lactic acid)) and PEG-b-PHis block copolymers by Lee et al (46) in which the targeting moiety, biotin, was masked until the carrier was exposed to an expected environment of $\mathrm{pH} 7.0$. Once the nanocarrier was internalized to cancer cells by ligand- receptor interactions, lowered $\mathrm{pH}(<6.5)$ destabilized the carrier resulting in a burst release of the loaded drug and that of Lukyanov et al (47), where a pH-degradable PEG-b-phosphatidylethanolamine (PE) liposome had anti-myosin monoclonal antibody as well as TAT or biotin attached on its surface.

\subsection{Organic/inorganic composites}

An inorganic-organic composite usually comprises an inorganic phase and a film forming organic phase. A typical green approach to developing an inorganic-organic composite involves the selection of film forming organic phase from starches having a degree of polymerization; degree of substitution and viscosity such that the substituted starches are insoluble in water during mixing but dissolve at a higher processing temperature during forming, setting or drying of the composite. Thus, excessive migration of the starch is prevented and the composite is substantially strengthened. There has also been reports on the lab-on-a-chip approach $(48-54)$, which embodies micron- or nano-sized machines composed of sophisticated circuits. Small devices have many advantages including portability/disposability, low cost, high reproducibility, high-throughput screening, and multiple functionalities in a single device. Recently, combined with other technologies such as optics, single molecular imaging, or cell/protein-based assay systems, biomedical lab-ona-chip devices have become an important part of drug discovery and diagnosis, but its application in drug delivery systems based on are just beginning to appear (55-57).

As rightly noted by several authors, to release a drug from a nanodevice is more complicated than to perform assay or screening drug candidates, this is because, successful drug delivery requires at least four components namely; drug reservoir, pump, valve, and sensor (58). Drugs can be placed either in a fabricated reservoir or in conventional micro/nanoparticles. Other important organic/inorganic composites are metal nanoparticles, such as silver, iron oxide, or gold nanoparticles, coated with hydrophilic polymers. Their major application has been as theranostics. Only recently, Hirsch et al, (59) developed gold nanoshell, which provided tunable emission light for bioimaging. Importantly, is the fact that, gold nanoparticles can be detected by X-ray and emit thermal energy by excitation making it very useful for medical imaging and thermal therapy (theranostics). In a related report, Corot et al, (60) developed super paramagnetic iron oxide nanoparticles for magnetic resonance imaging (MRI) of the whole body. Mechanistically, these nanoparticles are primarily engulfed by monocyte or macrophage after intravenous administration. However, uptake of super paramagnetic iron oxide by macrophage does not induce activation of nearby cells making it suitable for diagnosis of inflammatory or degenerative diseases. 


\section{Nanoparticulate drug delivery systems}

\subsection{Liposomes}

Use of micro and nano particles in biomedicine and especially in drug delivery has a great deal of advantages over conventional systems such as: the enhanced delivery, high performance characteristics of the product, use of lesser amounts of expensive drugs in the delivery systems, extension of the bioactivity of the drug by protecting it from environmental effects in biological media, more effective treatment with minimal side effects. In addition, research for the design of more effective delivery systems is more economical for the discovery of a new bioactive molecule. Micro and nano colloidal drug delivery systems such as emulsions, suspensions and liposomes have been used for decades for this purpose and recently, nanosized systems with dimension of less than $100 \mathrm{~nm}$ gained significant attention. Nanotechnology promises to generate a library of sophisticated drug delivery systems that integrate molecular recognition, diagnostic and feedback. Nanotechnology is expected to create lots of innovations and play a critical role in various biomedical applications including the design of drug and gene delivery systems, molecular imaging, biomarkers and biosensors. By understanding the signaling and interaction between the molecules at nano levels, it would be possible to mimic biological systems.

Liposomes are small spherical vesicles (Fig. 2) in which one or more aqueous compartments are completely enclosed by molecules that have hydrophilic and hydrophobic functionality. Liposomes vary with composition, size, surface charge and method of preparation. They can be single or in multiple bilayers. Those containing one bilayer membrane are termed small unilamellar vesicles or large unilamellar vesicles based on their sizes (61). If more than one bilayer is present then they are called multilamellar vesicles. Liposomes are commonly used as model cells or carriers for various bioactive agents including drugs, vaccines, cosmetics and nutraceuticals. Drugs associated with liposomes have markedly altered pharmacokinetic properties compared to free drugs in solution. Liposomes are also effective in reducing systemic toxicity and preventing early degradation of the encapsulated drug after administration. They can be covered with polymers such as polyethylene glycol (PEG) - in which case they are called pegylated or stealth liposomes, in this form, they usually will exhibit prolonged half-life in blood circulation. Liposomes can also be conjugated to antibodies or ligands to in order enhance target-specificity. For example, Visser et al (62) studied pegylated horse -radish-peroxidase loaded liposomes, tagged with transferrin to the blood-brain barrier. The authors showed an effective targeting of liposomes loaded with protein or peptides to the brain capillary endothelial cells and suggested that the system could be an attractive approach for targeting drug delivery to brain. In another report, Lopez-Pinto and coworkers (63) examined the dermal delivery of a lipophilic drug, minoxidil, from ethosomes versus classic liposomes by applying the vesicles non-occlusively on rat skin, yet in a separate study, Ozden and Hasirci (64) prepared small unilamellar vesicles composed of phosphatidyl- choline, dicetyl phosphate and cholesterol and entrapped glucose oxidase in them. Liposomes are also studied as carriers for cells, genes or DNA fragments. Ito et al (65) studied the effect of magnetite cationic liposomes which have 
positive surface charge to enrich and proliferate Mesenchymal stem cells (MSCs) in vitro. Kunisawa et al (66) established a protocol for the encapsulation of nanoparticles in liposomes, which were further fused with ultra violet-inactivated Sendai virus to compose fusogenic liposomes and observed that fusogenic liposome demonstrated a high ability to deliver nanoparticles containing DNA into cytoplasm.

Foco et al (67) studied the delivery of sodium ascorbyl phosphate (SAP), an effective oxygen species scavenger to prevent the degenerative effects of UV radiation on skin. SAP was encapsulated into liposomes to improve its penetration through the stratum corneum into the deeper layers of the skin. Sinico et al (68) studied transdermal delivery of tretinoin and examined the influence of liposome composition, size, lamellarity and charge on transdermal delivery. They studied positively or negatively charged liposomes of different types. It was reported that negatively charged liposomes strongly improved newborn pig skin hydration and tretinoin retention. Arcon et al (69) encapsulated an anticancer agent, cisplatin, in sterically stabilized liposomes and studied the systems with extended X-ray absorption fine structure method, and concluded that the liposome-encapsulated drug is chemically stable and does not hydrolyze.

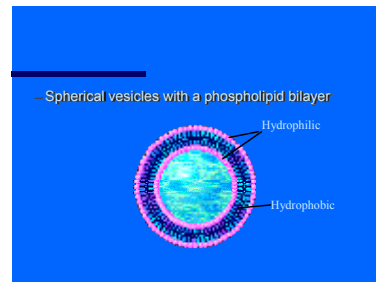

Figure 2. Spherical vesicles with a phospholipid bilayer

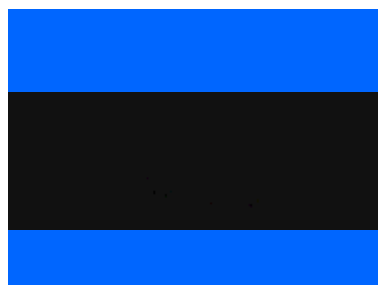

Figure 3. Cell Membrane

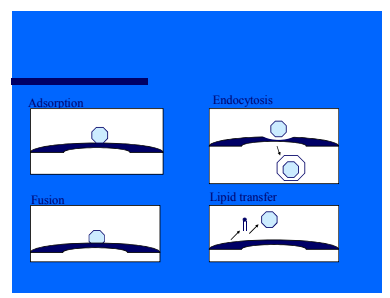

Figure 4. Modes of Liposome/Cell Interaction 


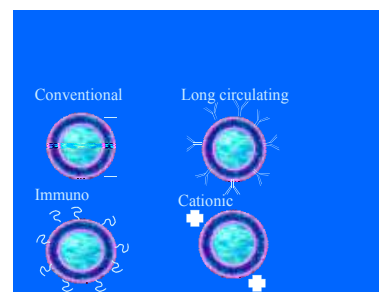

Figure 5. Classes of Liposomes

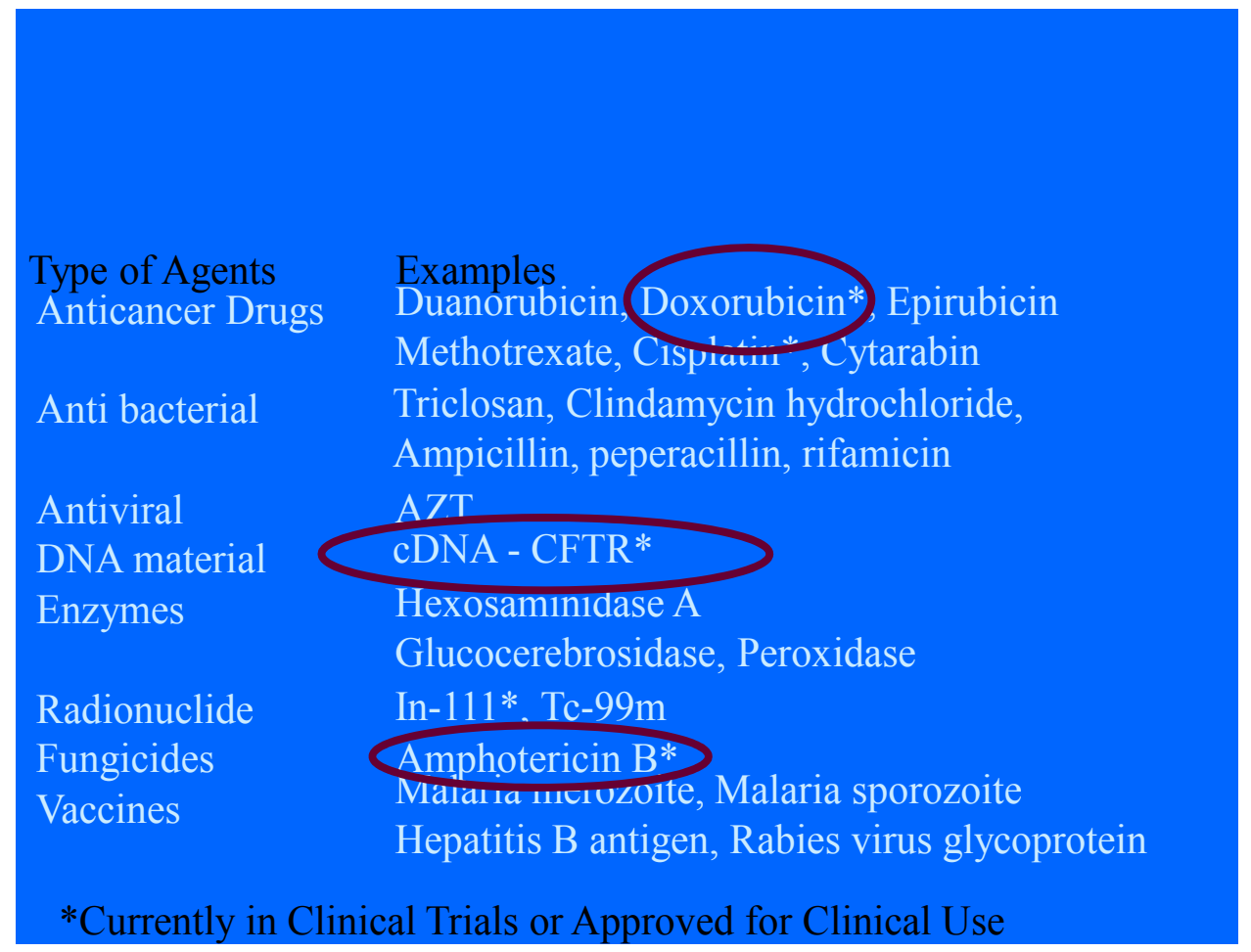

Source: Jessica Scott, www.nanobiotec.iqm.unicamp.br

Table 1. Current liposomal drug preparations

\subsection{Microemulsions}

Microemulsions are isotropic, thermodynamically stable systems composed of oil, water, and surfactant. Thermodynamic stability rather than size, is the defining hallmark of a microemulsion, although the droplet sizes are still below $100 \mathrm{~nm}$ (and many times much smaller) (70). Be that as it may, what is critical about microemulsions is that, they contain two phases consisting of two immiscible liquids that are mixed together and stabilized with the aid of a surfactant with or without a co-surfactant. They may have droplets in the range 


\begin{tabular}{|c|c|c|}
\hline Liposome Utility & Current Applications & Disease States Treated \\
\hline Solubilization & Amphotericin B, minoxidil & Fungal infections \\
\hline Site-Avoidance & $\begin{array}{l}\text { Amphotericin B - reduced } \\
\text { nephrotoxicity } \\
\text { doxorubicin - decreased cardiotoxicity }\end{array}$ & Fungal infections, cancer \\
\hline Sustained-Release & $\begin{array}{l}\text { Systemic antineoplastic drugs, } \\
\text { hormones, corticosteroids, drug depot in } \\
\text { the lungs }\end{array}$ & Cancer, biotherapeutics \\
\hline Drug protection & Cytosine arabinoside, interleukins & Cancer, etc. \\
\hline RES Targeting & $\begin{array}{l}\text { Immunomodulators,vaccines, } \\
\text { antimalarials,macophage-located } \\
\text { diseases }\end{array}$ & Cancer, MAI, tropical parasites \\
\hline Specific Targeting & Cells bearing specific antigens & Wide therapeutic applicability \\
\hline Extravasation & $\begin{array}{l}\text { Leaky vasculature of tumors, } \\
\text { inflammations, infections }\end{array}$ & Cancer, bacterial infections \\
\hline Accumulation & Prostaglandins & Cardiovascular diseases \\
\hline
\end{tabular}

Source: Handbook of Biological Physics Volume 1, (ed. R. Lipowsky and E. Sackmann). Elsevier Science B. V.

Table 2. Some applications of liposomes in the pharmaceutical industry

of $5-100 \mathrm{~nm}$. The difference between microemulsions and emulsions is that, the later are opaque mixtures of two immiscible liquids, thermo- dynamically unstable and usually require the application of high torque mechanical mixing or homogenization to produce dispersed droplets in the range of $0.2-25 \mathrm{~mm}$. Both types can be made as water-in-oil (w/o) or oil-in-water $(\mathrm{o} / \mathrm{w})(70)$. Choice of the dispersed and continuous phases for microemulsions formulations is based on the hydrophilicity of the model drug. Also, surfactants that have hydrophilic-lipophilic balances (HLB) of 3-6 tend to promote the formation of w/o microemulsions while those with HLB values of 8-10 tend to promote the formation of $\mathrm{o} / \mathrm{w}$ microemulsions. It has been reported (70) that, the formation and stability of microemulsions are dependent on the interfacial tension between the dispersed and continuous phases. Microemulsion instability can lead to Oswald ripening leading to dissolution of the small droplets with a resultant increase in the size of the large droplets, therefore, stabilization against Ostwald ripening is very critical, this is because, the resultant change in the size of the droplets could lead to loss of physical stability of the dosage form. Choice of the components of microemulsions affects its stability (70). Safety is also another important factor that must be considered during component selection. Attwood, 1994 had opined that, the irritant and toxic properties of some alcohols (1-butanol and 2-butanol) 
could limit their potential use. Microemulsions have been proposed as drug delivery systems to enhance the absorption of drug across biological membranes (70). Some of the advantages of microemulsions include (i) Increased solubility and stability of drugs (ii) ease and economy of scale-up. Some of the disadvantages are; (a) premature leakage/release of incorporated drug (b) phase inversion (c) Many of the effective surfactants and/or cosurfactants do not have a pharmaceutically acceptable toxicity profile; and (d) microemulsion systems often require development of complex systems that may be time consuming.

\begin{tabular}{|c|c|c|}
\hline Product & Developed & Applications \\
\hline Rapamune ${ }^{\circledR}$ & Elan's & An immunosuppressant \\
\hline Emend $\circledast$ & Elan's & Anti-nausea \\
\hline Estrasorb $®$ & Elan's & Topical estrogen therapy \\
\hline Megace $®$ ES & Elan's & Stimulate appetite \\
\hline TriCor $®$ & Elan's & Cholesterol-lowering \\
\hline Abraxane $®$ & APP & Breast cancer \\
\hline Doxil@ & Alza & Anti-cancer \\
\hline Acticoat $(8$ & Smith \& Nephew & Antimicrobial \\
\hline SilvaGard & AcryMed, Inc., & Antimicrobial \\
\hline
\end{tabular}

Source: B. K. Nanjwade, Department of Pharmaceutics, KLE University College of Pharmacy, BELGAUM-590010

Table 3. Some medical applications of liposomes

\subsection{Nanoparticles}

Nanoparticle drug delivery systems are nanometeric carriers used to deliver drugs or biomolecules. Generally, nanometeric carriers also comprise sub-micron particles with size below $1000 \mathrm{~nm}$ and with various morphologies, including nanospheres, nanocapsules, nano- micelles, nanoliposomes, and nanodrugs, etc. (71, 72). Nanoparticle drug delivery systems have outstanding advantages, some of which include; (1) they can pass through the smallest capillary vessels because of their ultra-tiny volume and avoid rapid clearance by phagocytes so that their duration in blood stream is greatly prolonged; (2) they can penetrate cells and tissue gap to arrive at target organs such as liver, spleen, lung, spinal 
cord and lymph; (3) they could show controlled- release properties due to the biodegradability, $\mathrm{pH}$, ion and/or temperature sensibility of materials; (4) they can improve the utility of drugs and reduce toxic side effects. As drug delivery system, nanoparticles can entrap drugs or biomolecules into their interior structures and/or absorb drugs or biomolecules onto their exterior surfaces. Presently, nanoparticles have been widely used to deliver drugs, polypeptides, proteins, vaccines, nucleic acids, genes and so on. Over the years, nanoparticle drug delivery systems have shown huge potential in biological, medical and pharmaceutical applications (73). Currently, the researches on nanoparticle drug delivery system focus on: (1) the selectness and combination of carrier materials to obtain suitable drug release speed; (2) the surface modification of nanoparticles to improve their targeting ability; (3) the optimization of the preparation of nanoparticles to increase their drug delivery capability, their application in clinics and the possibility of industrial production; (4) the investigation of in vivo dynamic process to disclose the interaction of nanoparticles with blood and targeting tissues and organs, etc. One type of nanoparticle, which is differentiated from any of the above terms, is a solid lipid nanoparticle (SLN) with a lipid core that is solid at room temperature. During formation of SLNs the solid lipid is first melted, then emulsified as a liquid to form an o/w emulsion, and cooled to allow the lipid to solidify. Due to the similarity in formation and content, these particles have been referred to as "emulsions with solid fat globules".

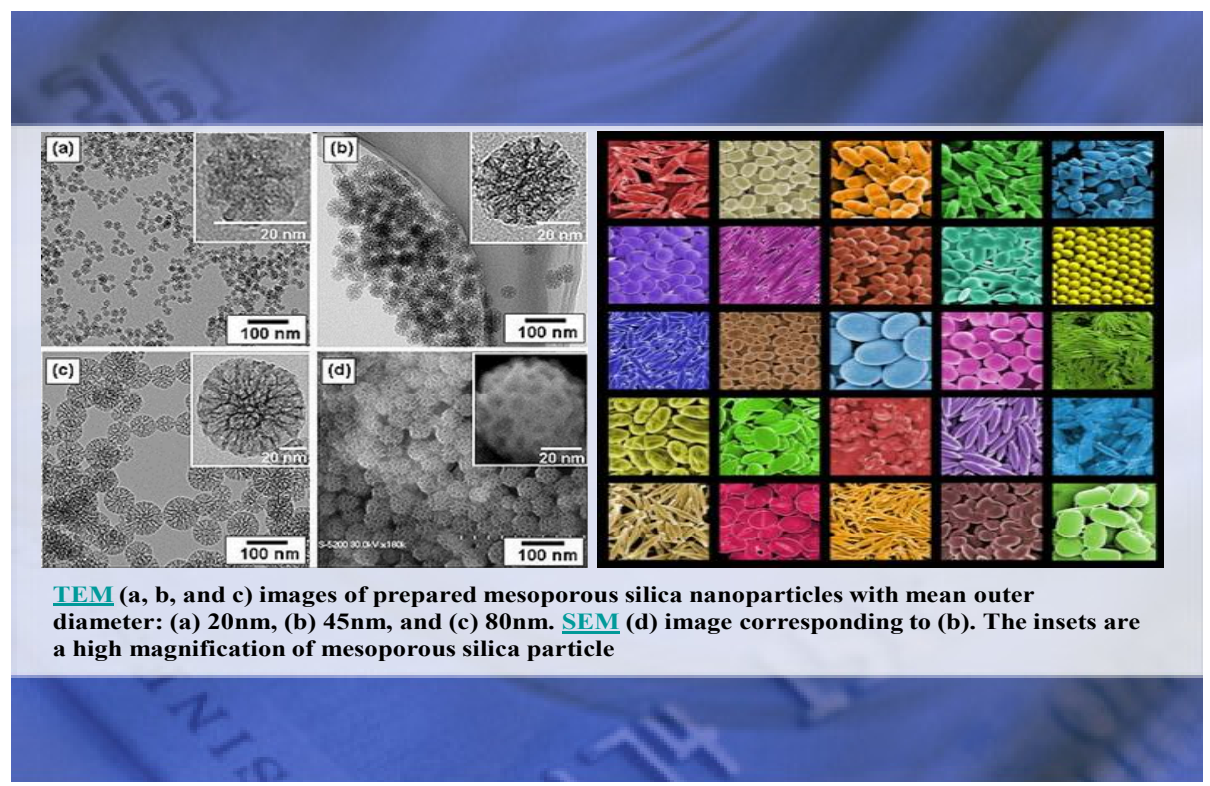

Source: B. K. Nanjwade api.ning.com/.../DevelopmentofNanotechnologyBasedDrugsanditsGu

Figure 6. Transmission and electron micrographs of silica nanopartcles

Nanoparticles are solid colloidal particles, ranging in size from 1 to $1000 \mathrm{~nm}$, consisting of various macromolecules in which the therapeutic drugs can be adsorbed, entrapped or 
covalently attached. The distinct advantages offered by solid nanoparticles in drug development can be ascribed to their physical stability and the possibility of modifying the formulating materials in order to achieve controlled release characteristics. The ability to formulate nanoparticles to achieve sustained release offers an opportunity for product life cycle management by developing formulations with decreased dosing frequency for drugs that are going off patent. There has been a variety of materials used to engineer solid nanoparticles both with and without surface functionality. Perhaps the most widely used are the aliphatic polyesters such as poly (lactic acid) (PLA), the more hydrophilic poly (glycolic acid) (PGA) and their copolymers poly (lactide-coglycolide) (PLGA). The degradation rate of these polymers and often the corresponding drug release rate can vary from days (PGA) to months (PLA). The effectiveness of nanoparticles in drug delivery can be attributed to many factors such as physical and biological stability, good tolerability of the components, simplicity of the manufacturing process, possibility of facile scale-up of the manufacturing process, amenability to freeze drying and sterilization.

\section{Some natural polymers in nanodrug delivery}

\subsection{Starch}

Starch is a common polysaccharide. It occurs majorly in plants where they act as storage materials. Chemically, it is composed of recurring units of glycopyranose in an alpha D-(1, 4) linkage and on hydrolysis yields the monosaccharide, glucose (Heller et al., 1990). The use of starch in pharmaceutics is extensive. It is used as co-polymer and excipient in controlled drug delivery (74-76) as drug carriers in tissue engineering scaffolds (77) as Hydrogels (78) and as solubility enhancers (79).

Santander-Ortega et al. (80) investigated the potential of starch nano-particles as a transdermal drug delivery system (TDDS). The challenge faced in delivering drug through these systems is that the skin acts as an effective barrier to drug passage and must therefore be overcome for effective drug delivery. Nano-particles were shown to facilitate drug delivery without interference to the skin's integrity. The method used to prepare the nano-particles was emulsification-diffusion due to its reproducibility, higher yields, ease of scale-up and control over size of particles and degree of polydispersity. Maize starch modified and un-modified (by the addition of propyl groups) was used as polymeric material to formulate 2 different types of nano-particles. The modified starch nano-particles were shown to be non-toxic using LDH (Lactose dehydrogenase) and MTT assay and resulted in particles of uniform size distribution while the nano- particles formulated from the native starch was not observable. Flufenamic acid, caffeine and testosterone were used as model drugs and their delivery across the skin was analyzed using excised skin from female Caucasian patients who had undergone abdominal plastic surgery. Permeation data obtained for caffeine and testosterone were similar for nano-encapsulated and free drugs while the delivery of flufenamic acid using the nanoparticles was enhanced by about ten-fold.

Starch nano-particles have been employed to deliver insulin via non-invasive routes; Makham (81) investigated the use of chitosan cross linked starch polymers as carriers for 
oral insulin delivery, manipulating the bio-adhesive and not so adhesive properties of chitosan and carboxymethyl starch to formulate hydrogels loaded with insulin. The authors however noted that, Insulin delivered by this method however faces the challenge of being broken down by proteases.

The nasal route can also be considered as an alternative to the subcutaneous route of administration because it is highly vascularised and is of great benefit in drug delivery as drugs given through this route are not subject to first-pass metabolism. However for effective delivery through this route, it is crucial that barriers to nasal drug delivery which include the lipophilic epithelium and muco-ciliary clearance must be overcome. Jain et al., (82) reports a size dependent insulin release in rats from starch nano-particles. Potato starch was used to prepare 2 differents types of nano-particles by cross-linking with epichlorohydrin and phosphoryl chloride $\left(\mathrm{POCl}_{3}\right)$ using both the gel and emulsion methods. These methods however led to the production of polydispersed nano-particles. There were statistically significant differences in mean sizes except in emulsion prepared epichlorohydrin cross linked particles which were smaller and of uniform distribution. Invitro studies showed that drug release followed first order kinetics and was diffusion controlled along with burst effect, due to the presence of left-over insulin on the surface of the nanopartices after entrapment. Emulsion cross-linked particles released their drug faster than gel cross linked particles with $85-90 \%$ and $81 \%$ release in $12 \mathrm{hrs}$ respectively. These differences were attributed to the diffusion path length of the drug within the particles. The smaller the particle size the less distance the drug will travel to be released. Tests carried out on the diabetes induced rats showed a 50-65\% reduction in blood glucose by nanoparticles compared to plain insulin formulation which served as control and this lasted for about 6hrs. Permeation enhancers modulated the hypoglycaemic effect and bioavailability of nano-particles, Plasma insulin levels of small sized nano-particles were also found to be significantly higher. Conclusions obtained from the study however recommend that further work would be needed in order to produce a more efficient carrier system.

Simi and Abraham (83) note that the presence of hydroxyl groups on starch enhances its hydrophilicity and confers on it low moisture resistance. This property poses a major constraint in drug delivery as a result of which it is often necessary to modify the polymer before it is made into nano particles as observed above. In their study, starch extracted from cassava tuber was modified by graft co-polymerization using long chain fatty acids before the resulting polymer was made into nano-particles (83). The nano-particles were prepared by dialysis and subsequently crosslinked using sodium tripolyphosphate. Oleic acid and stearic acid were both used as fatty acids while indomethacin was used as model drug. Findings showed that drug release from both types of nano-particles was effectively controlled. It is however not clear whether there was a significant difference between drug releases in both types of nano-particles. No attempts were also made to formulate the unmodified starch granules into nano-particles though this may have been due to results obtained from differential scanning calorimetry which showed that native starch was less processable than grafted starch. 
In addition, magnetised iron-oxide nano-particles coated with starch were used by Cole et al. (84) as a means of targeting brain tumours. Magnetic resonance imaging and histological reports showed that surface modification with polyethylene oxide improved delivery to tumour cells resulting in a greater accumulation of particles in the glioma compared to the rest of the brain.

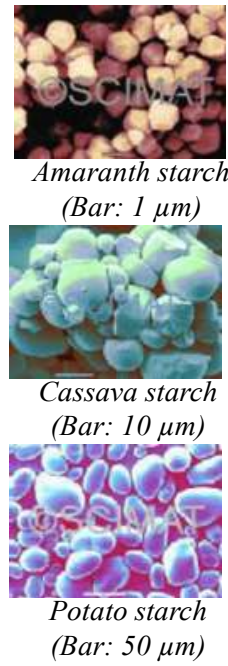

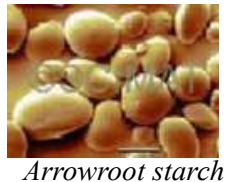

(Bar: $20 \mu \mathrm{m})$

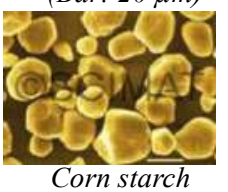

(Bar: $10 \mu \mathrm{m})$

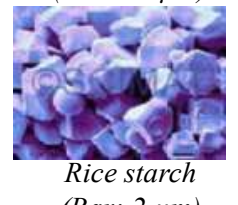

(Bar: $2 \mu \mathrm{m}$ )

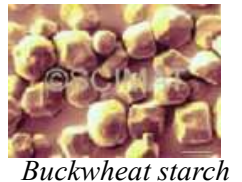

(Bar: $5 \mu \mathrm{m}$ )

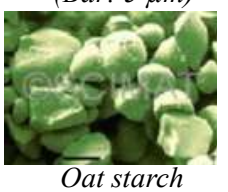

(Bar: $5 \mu \mathrm{m})$

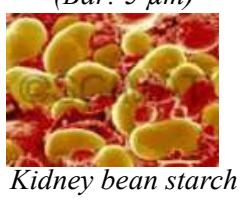

(Bar: $20 \mu \mathrm{m}$ )

Figure 7. Granule structure of some common native starches

\subsection{Chitosan}

This polymer is obtained from the partial N-deacetylation of chitin found in the shells of crustacean. It is composed of glucosamine and $\mathrm{N}$-acetyl glucosamine linked by $\beta$ 1-4 glucosidic bonds and is one of the most widely studied natural polymers for nano-drug delivery. The deacetylation of chitin is both concentration and temperature dependent with optimal yields achieved at temperatures between $60^{\circ} \mathrm{C}-80^{\circ} \mathrm{C}$ using $50 \% \mathrm{w} / \mathrm{w}$ alkali (85).

Park et al.,(86) in a review on chitosan describes its numerous applications in delivering low molecular weight drugs and summarises the reason for its choice being in its physiochemical and biological properties, enabling chemical modification and enhanced residence time respectively. It has been used as both a composite membrane with collagen (87) and a cross linked polymer for transdermal delivery of propranolol (88).

Nano-particles fabricated with chitosan as co-polymer was used to by Dev et al., (89) to investigate the controlled release of anti-retroviral drug, lamivudine. The nano-particles were prepared by emulsion and solvent evaporation technique and characterised using dynamic light scattering. The use of this method resulted in monodispersed particles with a 
size range of 300-350nm. Two formulations with differences in percentage drug weight (3\% and $6 \%$ ) were made, of which drug release rate was higher from the nano-particles with higher drug loading, though both were able to control drug release fairly well. Drug release kinetics showed that the mechanism of drug release was by diffusion. Conclusions reached suggested that the nano-particles could be applied for gastrointestinal drug delivery because drug release was relatively slower at neutral $\mathrm{pH}$ compared to acidic $\mathrm{pH}$ and also slower in the acidic $\mathrm{pH}$ compare to the alkaline $\mathrm{pH}$.

Chitosan combination was also used by Menon et al. (90) for therapeutic drug delivery. Nano-complexes of chitosan and polyoxometalates (POM) were tested as anti-cancer preparation. Since POM's though toxic have shown promise in being used as anti- viral and anti-tumour agent, the role of chitosan was to minimise the toxicity associated with POM, by modifying its surface properties. Mono-dispersed particles with size 200nm were produced using ionotropic gelation technique and the use of probe sonication was shown to control particle size and distribution compared to ultrasonication. In-vitro studies showed that the nano-complex was able to sustain drug release with enhanced anti-tumour activity at much lesser doses than the POM alone.

Similarly as with starch nano particles, Luo et al. (91) used chitosan oligosaccharides (COS) to coat lipid based carriers in order to enhance ocular drug delivery. This material is obtained from the decomposition of chitosan, but it is more soluble in water than chitin and chitosan. Drug introduced into the eye have minimal residence times as they are quickly washed away and have to be re-administered regularly. But in this study, COS enhanced permeation and adhesion of the cornea. There was a 7.7 fold and 2.8 fold retention of the model drug, flubiprofen by the COS coated nano lipid carriers compared to the phosphate buffer solution and uncoated nanolipid carriers which were attributed to the mucoadhesive properties of COS. The use of COS was also found to be non-irritating to the eye, a property which is of utmost importance in the choice of a suitable eye formulation.

\subsection{Gelatin}

Gelatin is obtained from the breakdown and hydrolysis of collagen, obtained from the connective tissues, bones and skins of animals. It is a known matrixing agent drug delivery. Bajpai and Shoubey (92) describes a process for the controlled release of sulphamethoxazole using 2 different gelatin nano-particles \{Type A (porcine skin) and type B gelatin( bovine skin)\} and cross linked with gluteraldehyde; Nano-particles of varying gelatin concentrations were prepared by solvent evaporation techniques and drug release kinetics evaluated using appropriate kinetic models. Findings from this system suggest that this system could be of use in targeted drug delivery such as colon drug delivery where $\mathrm{pH}$ is an important consideration. Drug release was found to increase following increased swelling of the nanoparticles. In addition, swelling was further enhanced by an increase in $\mathrm{pH}$ with greater drug release occuring at $\mathrm{pH} 7.5$ than at $\mathrm{pH}$ 1.8. The nano particles were also not degraded in simulated gastric fluid thereby showing 
their stability under acidic conditions. An increase in concentration of the cross linker led to an increase in swelling and drug release up until a certain concentration $(10.6 \mathrm{mM})$ when swelling began to decline. This relationship between the amount of cross linker and the polymer has also been reported by Das et al. (93); In their case, nano-particles composed of gelatin blended with montmorillonite (MMT) were loaded with the anti-cancer agent paclitaxel. These nano-particles were prepared by the same method of solvent evaporation and produced similar results. Increase in gluteraldehyde concentrations was reported to increase swelling and consequently drug release up until a certain point, when further increases in concentration of the cross linker led to decreased swelling and drug release. There was also a cumulative increase in drug release with increased $\mathrm{pH} .80 \%$ of the drug was released within $8 \mathrm{hrs}$ at $\mathrm{pH} 7.4$ while there was less than $44 \%$ drug release within $4 \mathrm{~h}$ at $\mathrm{pH}$ 1.2. Increasing concentration of the loaded drug also led to an increase in drug release.

The use of proteins as nano carriers is also employed in gene therapy. Viral and non-viral vectors are used for the transfection of DNA into cells, because, the injection of naked DNA into living tissue results in enzymatic degradation and reduced cellular uptake due to repulsion between the negatively charged DNA and cell membrane. In this domain, Coester et al., (94) used avidin modified gelatin nano-particles for the delivery of biotinylated PNA (Peptide nucleic acids) in other to investigate their use as anti-sense therapy. Zwiorek et al. (95) suggests that gelatin nano- particles have the potential to be used for effective non-viral gene delivery and are a safer alternative to the use of viral vectors. A 2 step desolvation process was used to prepare cationized particles of uniform size distribution and low polydispersity and comparisons between polyethyleneimine- DNA complexes and the gelatin particles showed that the latter is effective in facilitating gene expression, has less toxic and better tolerated.

Transfection with the aid of gelatin nanoparticles was also used by $\mathrm{Xu}$ et al. (96) for the delivery of DNA plasmids encoding for insulin growth like factor 1(IGF-1) into chrondrocytes. In order to incorporate the plasmids into the gelatin nano-particles, complex coacervation was employed because it is an easy, fast and particularly useful method for the incorporation of large molecules. The authors proved that, cationized gelatin particles were of smaller sizes than non- cationized particles, this they attributed to the condensation of the cationized particles. Fluorescence spectroscopy showed that the cationized gelatin nanoparticles were successfully transfected and expressed the gene while the reverse was the case for the non-cationized gelatin particles. This is probably due to enhanced endocytosis, occurring as a result of interactions between the positive charge on the former and the negative charge on the cell membrane. A 5-fold increase in growth factor production was observed in cells containing these nano-particles. Findings also showed that over expression of the gene was maintained steadily for up to 2 weeks when they were grown in collagen (type II) -glycosaminoglycan scaffolds in 3D culture. Since a prolonged and localized release of IGF-1 was achieved in this study, and IGF-1 is known to promote growth in skeletal muscle, cartilage and bones and numerous other tissues in the body tissue, this approach shows potential applications in gene therapy and tissue engineering. 


\section{Properties of nanoparticles}

Some of the properties of nanoparticles that are important for application in drug delivery include simple, affordable manufacturing process that is easy to scale up. The manufacturing process excludes organic solvents or potentially toxic ingredients. All the components of the formulation should be commercially available, safe, affordable, non-toxic and biodegradable. The nanoparticles should be stable with respect to size, surface morphology, size distribution and other important physical and chemical properties.

\section{Preparation of nanoparticles}

\subsection{Nanosuspensions}

Nanosuspension refers to production of sub-micron-sized particles by subjecting the combination of drug and a suitable emulsifier to the process of milling or high-pressure homogenization. Conventional milling and precipitation processes generally result in particles with sizes that are much greater than $1 \mathrm{~mm}$. As such, a critical step in the nanosuspension preparation is the choice of the manufacturing procedure to ensure production of sub-micron particles. Nanosuspension formulations can be used to improve the solubility of poorly soluble drugs. A large number of new drug candidates emerging from drug discovery programs are water insoluble, and therefore poorly bioavailable, leading to abandoned development efforts. These can now be rescued by formulating them into crystalline nanosuspensions. Techniques such as media milling and high-pressure homogenization have been used commercially for producing nanosuspensions. The unique features of nanosuspensions have enabled their use in various dosage forms, including specialized delivery systems such as mucoadhesive hydrogels. Nanosuspensions can be delivered by parenteral, per- oral, ocular, and pulmonary routes. Currently, efforts are being directed to extending their applications in site-specific drug delivery. Various particle sizes of spironolactone, a model low solubility drug, have been formulated to yield micro- and nanosuspensions of the type solid lipid nanoparticles and DissoCubes. The DissoCubes nanosuspension yielded highly significant improvements in bioavailability. Particle size minimization is not the major determining factor in the bioavailability improvement. Rather, the type of surfactant used as stabilizer in the formulations is of greater importance. Improvement in drug solubility in the intestine as well as in dissolution rate of spironolactone is the most likely mechanisms responsible for the observed effect, although additional mechanisms such as permeability enhancement may also be involved.

Development of nanoparticle formulations for improved absorption of insoluble compounds and macromolecules enables improved bioavailability and release (97)

Particle size reduction to sizes below $1 \mathrm{~mm}$ is usually difficult due to possible particle aggregation and generation of high surface area materials. Milling techniques that have been used to generate nano-sized particles are ball milling or pearl milling that applies milling beads of sizes ranging from 0.4 to $3 \mathrm{~mm}$ and these beads may be composed of glass, ceramics or plastics (98). The time required for milling depends on the hardness and 
brittleness of the drug material in comparison to milling material and inertial forces set up within the mill. Some of the challenges that milling processes can pose in drug development are (i) undesirable erosion of the milling equipment components into the drug product; (ii) the process is usually time consuming, thereby prolonging drug development time; (iii) milling over a few days may bring the risk of microbiological problems or increases in the cost of production; also (iv) prolonged milling may induce the formation of amorphous domains in crystalline starting materials or may lead to changes in the polymorphic form of the drug. The generation of amorphous form of the drug is problematic because these forms may crystallize during the shelf life of the drug leading to changes in solubility and bioavailability of the drug. An example of the conversion of crystalline to amorphous form of the drug was observed in jet milling of albuterol sulfate. Also, the generation of highenergy surfaces that affected wettability was observed with acetylsalicylic acid. Some examples of nano-sized particles produced by milling as reviewed by Majuru and Oyewumi (70) are (i) naproxen nanoparticles approximately $200 \mathrm{~nm}$ in diameter and (ii) danazol particles of a mean size of $169 \mathrm{~nm}$. The authors also reported that, there were four approved drug products in the USA that are based on NanoCrystal technology: (a) Rapamune (sirolimus) tablets by Wyeth; (b) Tricor (fenofibrate) tablets by Abbott; (c) Emend (aprepitant) capsules by Merck; and (d) Megace ES (megestrol) oral suspension by Par Pharmaceuticals (70). High pressure homogenization has also been recognized as an effective method of producing nanosuspensions (98). Again, Majuru and Oyewumi (70) reported that, high-pressure homogenization has been applied commercially with the development of some drug products, such as fenofibrate and paclitaxel. A typical procedure for preparing nanosuspension involves, preparing an aqueous suspension of drug in surfactant solution, this is then passed through a high pressure of typically 1500 bar at 3-20 homogenization cycles. The suspension is then passed through a small gap in the homogenizer of typical width $25 \mathrm{~mm}$ at 1500 bar. Due to built up cavitation forces that are created drug particles are broken down from micro to nanoparticles. An example is in the micro fluidization of atovaquone to obtain particles in the 100-300 nm size range Majuru and Oyewumi (70). It has been reported that, nanosuspension particles in most cases have an average size ranging from 40 to $500 \mathrm{~nm}$ with a small $(0.1 \%)$ proportion of particles larger than $5 \mathrm{~mm}$ Majuru and Oyewumi (70). Experts have recognized that, a major challenge in the use of high-pressure homogenization is the possible changes in drug crystal structure that may cause batch-to-batch variation in crystallinity level, and have suggested that, application in drug delivery should include the desired specification by which the quality of each batch will be evaluated.

\subsection{Polymeric nanoparticles}

Polymeric nanoparticles can be identified as submicronic (size $<1 \mu \mathrm{m}$ ) colloidal carriers. Compared to other colloidal carriers polymeric Nanoparticles hold significant promise for the advancement of treating diseases and disorders. They have attractive physicochemical properties such as size, surface potential, hydrophilic-hydrophobic balance and for this reason they have been recognized as potential drug carriers for bioactive ingredients such as 
anticancer drugs, vaccines, oligonucleotides, peptides, etc. Their widespread use for oral delivery also aims at improving the bioavailability of drugs with poor absorption characteristic, reducing GI mucosa irritation caused by drugs and assuring stability of drugs in the GI tract. Thus, all these and many more such characteristics of nanoparticles qualify them as a promising candidate in drug-delivery technology. Although various biodegradable nanoparticles of natural polymers such as starch, chitosan, liposomes etc, are largely in use as drug carriers in con- trolled Drug-delivery technology (99). Many FDAapproved biodegradable and biocompatible polymers have been used in nanoparticle preparation. These include polylactide-polyglycolide copolymers, polyacrylates and polycaprolactones. Nanoparticles can be prepared from polymerization of monomers or from preformed polymer with the possibility of performing many chemical modifications. The polymerization reaction in these systems generally occurs in two steps: a nucleation phase followed by a growth phase and the process can be carried out in two ways either as emulsion polymerization or as interfacial polymerization. When nanoparticle preparation involves polymerization, it is undesirable to have residual monomers and initiators in the final nanoparticle formulation. A critical step of the process is the purification and removal of residual monomers. It is also very important to separate free drugs from the drug loaded nanoparticle suspension. A potential challenge for polymeric nanoparticles is associated with residues from organic solvents and polymer toxicity. If the drug to be incorporated in nanoparticles is hydrophobic, the drug is dissolved or dispersed into the polymer solution. The polymer solution is then added to an aqueous solution, followed by high-speed homogenization or sonication to form an oil-in-water emulsion. Nanoparticle preparation is usually facilitated and stabilized with the aid of an emulsifier or stabilizer. If the drug to be incorporated in nanoparticles is hydrophilic, the drug is added to the aqueous phase and entrapped into nanoparticles through a double emulsification method to form water-in-oilin-water emulsion Majuru and Oyewumi (70). Residual organic solvent can be removed by evaporation or a decreased pressure or under a vacuum environment with or without the aid of inert gas flow. Solid nanoparticles are cured from the suspension by centrifugation, filtration or freeze drying. Another method is based on particle precipitation upon addition of a non-solvent to polymer solution under mechanical stirring. This method allows the formation of nanoparticles without prior emulsification. Nanoparticle formation and characteristics are dependent on the choice of the polymer/solvent/non-solvent system that will ensure mutual miscibility of the solvent and non-solvent of the polymer, Majuru and Oyewumi (70). Nanoparticles can also be prepared from natural macromolecules using methods such as thermal denaturation of proteins (such as albumin) or gelification process such as in alginates. In general, the controlling factors in the nanoparticle formulation process, which are adjustable for an ideal design, are the polymer type and its molecular weight, the copolymer blend ratio, the type of organic solvent, the drug loading level, the emulsifier/stabilizer and oil-water phase ratio, the mechanical strength of mixing, the temperature and the $\mathrm{pH}$. These authors have opined that, in production of a drug product it is important to set a limit for residual solvent in the formulation that is based on the acceptable daily intake and to develop analytical methods for testing of the solvent levels in 
the nanoparticles. Table 4 below shows some of the applications of polymeric materials in nanodrug delivery.

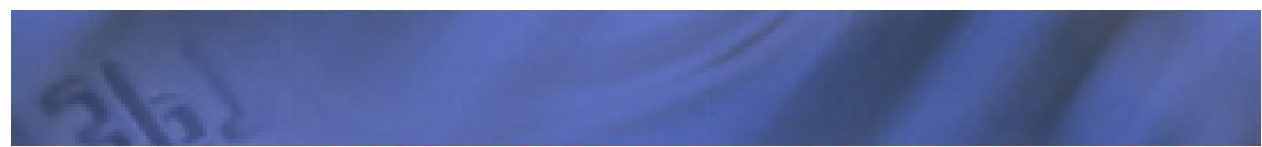

COLLOID BASED DELIVERY FOR THERAPEUTICS

\begin{tabular}{|c|c|c|c|}
\hline $\begin{array}{c}\text { Delivery system } \\
\text { type }\end{array}$ & $\begin{array}{l}\text { Typical mean } \\
\text { particle diameter } \\
\text { (in micrometers) }\end{array}$ & $\begin{array}{c}\text { Representative } \\
\text { systems of each } \\
\text { type }\end{array}$ & $\begin{array}{l}\text { Characteristic } \\
\text { applications }\end{array}$ \\
\hline $\begin{array}{l}\text { Microspheres, } \\
\text { Hydrogels }\end{array}$ & $0.5-20$ & $\begin{array}{l}\text { Alginate, gelatin, } \\
\text { chitosan, polymeric } \\
\text { hydrogels }\end{array}$ & $\begin{array}{l}\text { Sustained release of } \\
\text { therapeutics }\end{array}$ \\
\hline Microparticles & $0.2-5$ & $\begin{array}{l}\text { Polystyrene, } \\
\text { polylactide } \\
\text { microspheres. }\end{array}$ & $\begin{array}{l}\text { Targeted delivery of } \\
\text { therapoutics }\end{array}$ \\
\hline $\begin{array}{l}\text { Emulsions, } \\
\text { Microemulsions }\end{array}$ & $0.15-2$ & $\begin{array}{l}\text { o/w, wio, lipid } \\
\text { emulsions, orw } \\
\text { microemulsions. }\end{array}$ & $\begin{array}{l}\text { Control and targeted } \\
\text { delivery of } \\
\text { therapeutics }\end{array}$ \\
\hline Liposomes & $30-1000$ & $\begin{array}{l}\text { Phospholipid and } \\
\text { polymer based } \\
\text { billayer vesicles. }\end{array}$ & $\begin{array}{l}\text { Targeted delivery of } \\
\text { therapeutics }\end{array}$ \\
\hline Micelles & $3-80$ & $\begin{array}{l}\text { Natural and } \\
\text { symehetic surfactant } \\
\text { micelles. }\end{array}$ & $\begin{array}{l}\text { Targeted delivery of } \\
\text { therapeutics }\end{array}$ \\
\hline Nanoparticles & $2-100$ & $\begin{array}{l}\text { Lipid, Polymer, } \\
\text { Inorganic } \\
\text { nanoparticles. }\end{array}$ & $\begin{array}{l}\text { Targeted delivery of } \\
\text { therapeutics, in vivo } \\
\text { navigational devices }\end{array}$ \\
\hline Nanocrystals & 2-100 & Quantum dots & Imaging agents \\
\hline
\end{tabular}

Source: B. K. Nanjwade api.ning.com/../DevelopmentofNanotechnologyBasedDrugsanditsGu

Table 4. Polymer colloids for nanodrug delivery

\subsection{Polymers for gene delivery}

The delivery of nucleic acid into cells in vitro and in vivo is a critical technique for the study of genes and development of potential gene therapies. To fully utilize this potential, safer and more efficient vectors for delivery of genes are required. Current nucleic acid delivery falls into two major categories, viral and nonviral. In nonviral gene delivery, cationic lipids or polymers are used to both protect nucleic acids from degradation and facilitate entry into the target cells. The resulting complexes self-assemble via electrostatic interactions to form stable aggregates. Recent reports have discussed the promise of lipid-DNA (lipoplex) and polycation-DNA complexes (polyplexes) (77) as potential therapeutics, including recent efforts to incorporate bioresponsive chemistries for increased effectiveness. Successful gene transfer requires sufficient stability of DNA during the extracellular delivery phase, 
transportation through cell membranes and cytoplasm, and eventual disassembly and nuclear delivery. A molecular architecture that achieves all the requirements will most likely consist of a virus like layered structure incorporating several components. Though nonviral gene vectors can be efficient in vitro and in vivo, their uncontrolled and often undefined interactions under physiological conditions still represent a major obstacle to their use in gene therapy. In particular, it has been shown that nonviral gene vectors or their constituents interact strongly with negatively charged serum proteins and other blood components. Such opsonization alters the physicochemical characteristics of vectors, may interfere with vector targeting, and is of concern if vectors are to be applied in humans. Consequently, one major objective in nonviral vector development is to devise vectors that are inert in the in vivo environment during the delivery phase. Poly (ethylene glycol) (PEG) has often been used to confer to these drug carriers the desired stability during the extracellular delivery phase. The incorporation of PEG to lipo- or polyplexes has been proven effective in reducing undesired effects such as immune response, unspecific interactions, and degradation. PEGylation can be implemented by using PEGylated components in the initial complex formation. Alternatively, PEG shielding can be applied to preformed complexes in a secondary processing step by using either electrostatic selfassembly or chemical grafting. While PEGylation is a necessity to improve extracellular stability and circulation half-life, it often decreases the transfection efficiency due to reduced specificity and inhibited cell association and uptake. Incorporating receptor targeting or using bioresponsive linkers to release PEG have proven useful to overcome these intracellular barriers to efficient delivery (100). Previous work (100) with a copolymerprotected gene vector (COPROG), consisting of a branched polyethylenimine (bPEI)/ DNA polyplex subsequently shielded with a copolymer consisting of both PEG and anionic peptides (P6YE5C), showed the presence of the copolymer, which provides steric stabilization, protection from opsonization, and allows freeze-drying of the vector with little loss of activity. COPROG particles have proven to be effective gene delivery vectors with decreased cellular toxicity without impairing gene transfer. The decreased toxicity of COPROG is likely a result of the removal of unbound polycation by the excess anionic copolymer emphasizing the potential role of binding stoichiometry in three-component complexes. Likely due to their stabilizing and opsonization- inhibiting properties, COPROGs have proven advantageous in promoting the tranfection capacity of polyplexloaded sponges upon subcutaneous implantation, and when colyophilized with fibrinogen, are a simple means to achieve an injectable fibrin gene-activated matrix (100). At the level of research, many synthetic DNA particles have been prepared for transfection in cell cultures and in animal studies. However, several authors (70).are of the opinion that, certain issues must be addressed in the development of DNA particles with cationic polymers. These are (i) potential toxicity of cationic polymers especially when administered at high concentrations; (ii) instability of particles on storage; (iii) instability of DNA particle size and particle size distribution leading to undesirable particle aggregation; (iv) poor transfection efficiency; (v) poor stability in blood circulation; and (vi) high cost of scaling up the process to achieve reproducible product quality. 


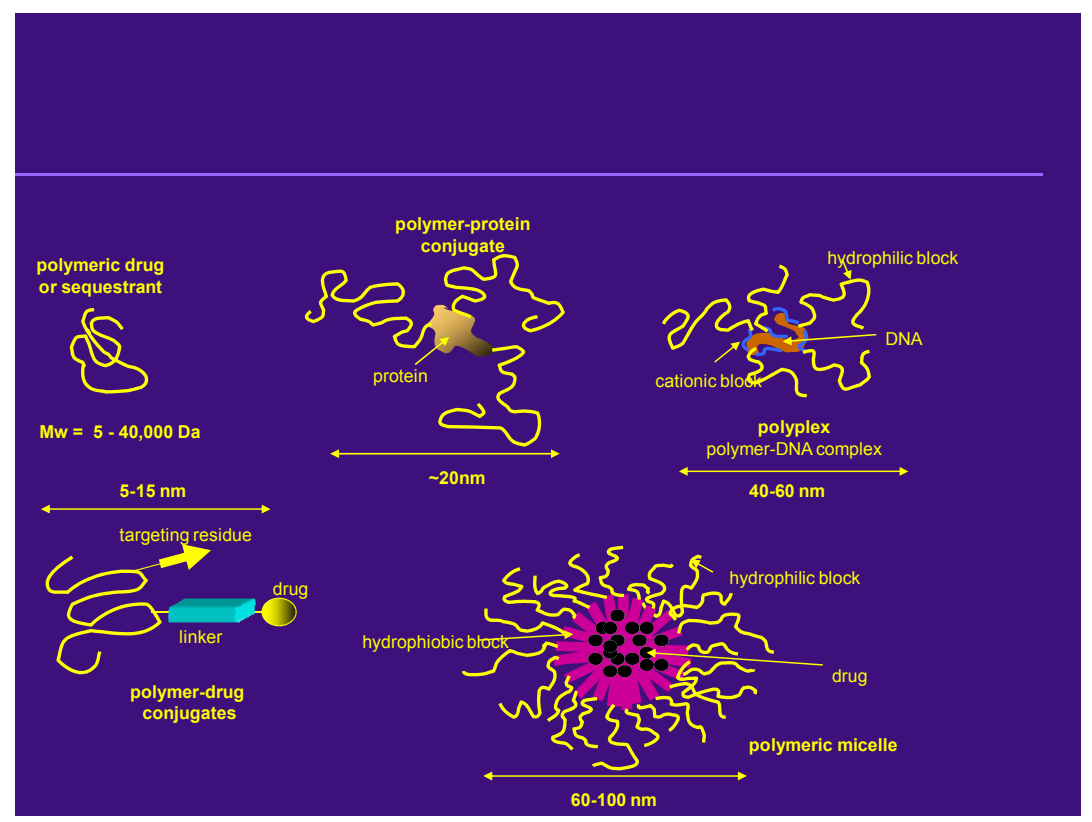

Figure 8. Nanosize medicines

\subsection{Solid lipid nanoparticles}

Solid lipid nanoparticles (SLN) are particles made from solid lipids with mean diameters ranging between $50-1000 \mathrm{~nm}$ and represent an alternative to polymeric particulate carriers. The main advantage offered by lipid carriers in drug delivery is the use of physiological lipids or lipid molecules with a history of safe use in human medicine, which can decrease the danger of acute and chronic toxicity (101). Sufficient data are available for the use of drug-loaded lipid nano and microparticles for oral delivery, the main mechanism of lipid particulate materials translocation across the intestine being the uptake via Peyer's patches. Research reported in literature (102) shows that SLN constituted of stearic acid and phosphatidylcholine were evidenced in lymph and blood after duodenal administration to rats: the small diameters of SLN may facilitate their uptake by the lymphatics. Up until today, only a few methods are described in the literature for SLN preparation, including high pressure hot homogenization and cold homogenization techniques (101) microemulsion-based preparation and solvent emulsification/evaporation method. Particularly, the emulsification/evaporation method concerns the preparation of nanoparticles dispersions from $\mathrm{O} / \mathrm{W}$ emulsions: the lipophilic material is dissolved in a water-immiscible organic solvent that is emulsified in an aqueous phase. Upon evaporation of the solvent, a nanoparticle dispersion is formed by precipitation of the lipid in the aqueous medium. Depending on the 
composition and the concentration of the lipid in the organic phase, very low particle sizes can be obtained, ranging from $30-100 \mathrm{~nm}$, but a clear disadvantage of this method is the use of organic solvents, whose toxicity cannot always be neglected. Recently, an emulsification-diffusion technique was developed using non-toxic and physiologically compatible solvents and monoglycerides or waxes as components of the disperse phase of oil-in-water emulsions obtained at $50{ }^{\circ} \mathrm{C}$ (103). The solvent-in-water emulsiondiffusion technique was before described in the literature mostly for the obtainment of polymeric micro- and nanoparticles and only a few authors proposed its application in the production of SLN (101). According to the moderate water solubility of the solvents employed, the dilution of the emulsions determined the diffusion of the organic solvent from the droplets to the continuous phase with the consequent instant solidification of lipophilic material. The emulsion compositions and process parameters used were the results of a formulative study aimed to develop optimized nanosphere formulations, whose mean sizes were below 200nm. In a separate report (104), the possibility of incorporating a peptide drug such as insulin in the SLN obtained with the developed method was considered, aiming to protect it from chemical and enzymatic degradation, as it is well-known that the incorporation of peptides in polymeric or non-polymeric particles should exert a certain protection of the drug against the proteolytic enzymes present in the gastrointestinal tract (101). Indeed, the use of lipids as matrix materials for sustained-release formulations for peptides and proteins has been reported only by few authors (101), owing to the hydrophobic nature of the lipid matrix that can be more appropriate to incorporate lipophilic drugs rather than hydrophilic proteins. An adequately high solubility of the drug in the lipid melt is therefore the pre-requisite to obtain a sufficient SLN loading capacity. Considering that the solubility of insulin in most commonly employed solvents and lipids is quite low, a specific solvent medium of the peptide was required. Isobutyric acid, a partially water-miscible solvent with low toxicity, revealed a totally unexpected high insulin-solubilization capacity at $50{ }^{\circ} \mathrm{C}$, further increasing when the solvent was water-saturated (104). Solid lipid insulin-loaded microparticles were therefore produced using isobutyric acid as a solvent. Preliminary analysis of microparticles content after processing showed an insulin-high encapsulation efficiency; moreover, insulin in SLN did not undergo any chemical modification and its in vitro release from the microparticles was very low, with an initial burst effect of $20 \%$ of the dose.

Of recent, SLN has become a popular drug delivery system for ophthalmic application. It is gaining prominence as promising approach to improve the poor ocular bioavailability of biomolecules. In particular, solid lipid nanoparticles (SLN) and nanostructured lipid carriers (NLC), regarded as the first and second generation of lipid nanoparticles are currently being applied.(105, 106) NLC was developed due by combining the advantages of SLN and avoidance of their limitations such as low drug loading capacity, poor longterm stability and early drug expulsion caused by lipid polymorphism.(107, 108) NLC consist of a mixture of spacially different solid and liquid lipids molecules, resulting in a structure with more imperfections in crystal lattice to accommodate drugs.(109, 110) As 
drug delivery devices, NLC show great promise for the eye, due to their better biocompatibility, modified drug release kinetics, reduction of drug leakage during storage, avoidance of organic solvents during production process and feasibility of large scale production. $(111,112)$

To prepare particles using the homogenization method, the drug is dissolved or solubilized in the lipid that has been melted and heated to a temperature approximately $5-10{ }^{\circ} \mathrm{C}$ above its melting point. For the hot homogenization technique, the drug dissolved in the lipid melt is dispersed under stirring in a hot aqueous surfactant solution of identical temperature. The obtained pre-emulsion is homogenized to produce nanoemulsions that are subsequently cooled to room temperature. Solid lipid nanoparticles are obtained upon lipid recrystallization at room temperature. Some of the process variables that will affect the particle size of nanoparticles as well as drug loading are (i) the type of homogenization technique; (ii) speed of homogenization; and (iii) rate of cooling in hot homogenization. Cold homogenization is applied for highly temperature-sensitive drugs and hydrophilic drugs. For the cold homogenization technique the drug containing lipid melt is cooled and ground to obtain lipid particles. The lipid particles are dispersed in a cold surfactant solution that is homogenized at or below room temperature. The process avoids or minimizes the melting of lipids and therefore minimizing the loss of hydrophilic drugs to the water surface. Solid lipid nanoparticles can also be prepared by using microemulsions as precursors.

\section{Characterization of nanoparticles}

Measurement of nanoparticles can be carried out by photon correlation spectroscopy (PCS) or dynamic light scattering (DLS). Photon correlation spectroscopy determines the hydrodynamic diameter of the nanoparticles by Brownian motion. In addition to the size, other important properties of nanoparticles include (i) density, molecular weight and crystallinity which can affect drug release and degradation; (ii) surface charge and hydrophobicity which may significantly influence nanoparticle behavior after administration. Zeta potential is also one of the properties of nanoparticles, and this is usually employed to measure the cell-surface charge density. The surface and bulk morphology are also important in determining the drug release kinetics of nanoparticles. Nanoparticles are usually visualized by scanning electron microscope (SEM) and atomic force microscopy (AFM). Thermal profile of nanoparticles can be studied using the differential scanning calorimetry (DSC), thermogravimetric analysis (TGA), while crystallinity can be monitored by x-ray crystallography. Other parameters which should normally be evaluated include; drug encapsulation efficiency; physical properties such as size, shape, stability of size, drug loading as well as drug release.

The common techniques for characterization as summarized by B. K. Nanjwade is shown in Tabs $5-8$ below: 


\begin{tabular}{|l|l|}
\hline \multicolumn{2}{|c|}{ Morphology } \\
\hline Properties & Common Techniques \\
\hline Size (primary particle) & TEM, SEM, AFM, XRD \\
\hline Size (primary/aggregate/agglomerate) & $\begin{array}{l}\text { TEM, SEM, AFM, DLS, FFF, AUC, } \\
\text { CHDF, XDC, HPLC, DMA(1) }\end{array}$ \\
\hline Size distribution & $\begin{array}{l}\text { EM, SEM, AFM, DLS, AUC, FFF, } \\
\text { HPLC, SMA }\end{array}$ \\
\hline Molecular weight & SLS, AUC, GPC \\
\hline Structure/Shape & TEM, SEM, AFM, NMR \\
\hline Stability (3D structure) & DLS, AUC, FFF, SEM, TEM \\
\hline
\end{tabular}

Source: B. K. Nanjwade api.ning.com/.../DevelopmentofNanotechnologyBasedDrugsanditsGu

Table 5 .

\begin{tabular}{|l|l|}
\hline \multicolumn{2}{|c|}{ SUrfaCe } \\
\hline P roperties & Common Techniques \\
\hline Surface area & BET \\
\hline Surface charge & SPM, GE, Titration methods \\
\hline Zeta potential & LDE, ESA, PALS \\
\hline Surface coating composition & SPM, XPS, MS, RS, FTIR, NMR \\
Surface coating coverage & AFM, AUC, TGA \\
\hline Surface reactivity & Varies with nanomaterial \\
\hline Surface-core interaction & SPM, RS, ITC, AUC, GE \\
\hline Topology & SEM, SPM, MS \\
\hline
\end{tabular}

Source: B. K. Nanjwade api.ning.com/.../DevelopmentofNanotechnologyBasedDrugsanditsGu

\section{Table 6.}

\begin{tabular}{|l|l|}
\hline \multicolumn{1}{l}{ Chemical } \\
\hline Properties & Common Techniques \\
\hline Chemical composition (core, surface) & $\begin{array}{l}\text { XPS, MS, AAS, ICP-MS, RS, FTIR, } \\
\text { NMR }\end{array}$ \\
\hline Purity & ICP-MS, AAS, AUC, HPLC, DSC \\
\hline Stability (chemical) & MS, HPLC, RS, FTIR \\
\hline Solubility (chemical) & Varies with nanomaterial \\
\hline Structure (chemical) & NMR, XRD \\
\hline Crystallinity & XRD, DSC \\
\hline Catalytic activity & Varies with nanomaterial \\
\hline
\end{tabular}

Source: B. K. Nanjwade api.ning.com/.../DevelopmentofNanotechnologyBasedDrugsanditsGu

\section{Table 7.}




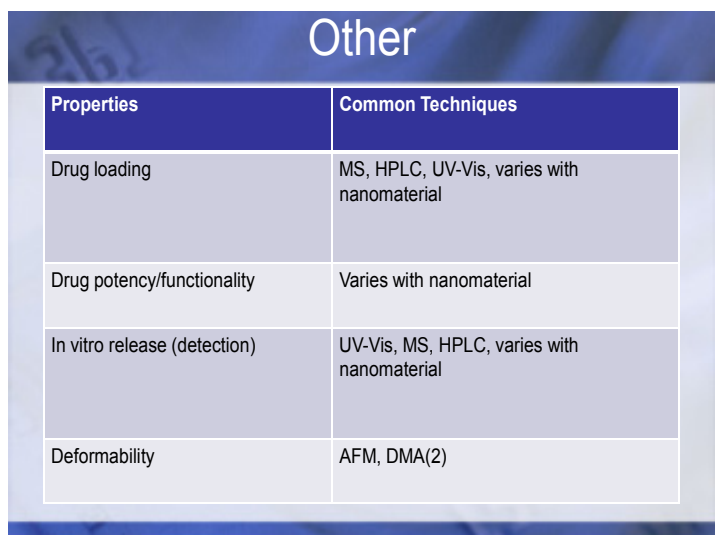

Source: B. K. Nanjwade api.ning.com/.../DevelopmentofNanotechnologyBasedDrugsanditsGu

Table 8.

\section{Nanoparticle application in non-parenteral applications}

\subsection{Oral administration}

For many reasons, oral drug delivery continues to be the preferred route of drug administration. It is the oldest and the commonest mode of drug administration as it is safer, more convenient, does not need assistance, non-invasive, often painless, the medicament need not be sterile and so is cheaper (113). However, the oral route is not suitable for drugs that are poorly permeable or easily degradable in the gastrointestinal tracts (GIT). For instance, delivery of proteins and peptides via the oral route will be greatly impacted by barriers such as (i) epithelial cell lining; (ii) the mucus layer; (iii) proteolytic enzymes in the gut lumen (such as pepsin, trypsin and chymotrypsin); and (iv) proteolytic enzymes (endopeptidases), at the brush border membrane. Drug loaded in nanoparticles will be protected from the enzymatic degradation along the GIT providing the potential benefit of enhanced absorption. It has been reported (70) that, particulate absorption takes place mainly at the intestinal lymphatic tissues (the Peyer's patches). The epithelial cell layer overlying the Peyer's patches contains Mcells. The differences between absorptive enterocytes and $\mathrm{M}$ cells are expressed in that $\mathrm{M}$ cells have (a) underdeveloped microvillous and glycocalyx structures, (b) apical microfolds, (c) increased intracellular vacuolization and (d) absence of mucus. The follicle-associated epithelia (FAE) are made up of the M cells and absorptive enterocytes (70). It has been reported that, the FAE and Mcells are predominantly responsible for particle uptake along the GIT. In this regard, nanotechnology is reportedly gaining attention in the development of proteins, peptides and DNA delivery systems (70).

\subsection{Pulmonary administration}

Micronization of drugs plays an important role in improving the drug dosage form and therapeutic efficiency today. If a drug is micronized into microspheres with suitable 
particle size, it can be addressed directly to the lung by the mechanical interception of capillary bed in the lungs. If a drug is prepared as microspheres in the size range of 7-25 $\mu \mathrm{m}$, the microspheres can be concentrated in lung through i.v. administration (114). This technique can improve pulmonary drug concentration to maximize its effectiveness against some pulmonary infections such as mycoplasmal pneumonia and minimize the adverse side effects. The final nanoparticulate formulation may be administered either as a nebulizer (metered dose inhalers) or dry powder inhalers. Local delivery of drugs to the lung is desirable for many clinical conditions such as asthma; chronic pulmonary infections, lung cancer and cystic fibrosis. For both local and/or systemic delivery, the effectiveness of drug delivery by inhalation may be greatly imparted by mucociliary clearance (70). Studies have shown that nanoparticles may facilitate transport of drugs to the epithelium while avoiding undesirable mucociliary clearance. Other benefits of nanoparticle-based formulations are in the suitability for (i) sustained drug effect due to possible prolonged residence of drug at the site of action or absorption; (ii) controlled or targeted drug delivery. The small size of nanoparticles makes them highly suitable for pulmonary delivery because they can easily be air borne and delivered to the alveolus. It is important that the components of the nanoparticle formulation are biodegradable to avoid accumulation in the lungs and that they do not cause irritation of the air ways and lung tissue. The control of the particle size of the formulation during manufacture and the entire shelf life of the drug product is also very important for an acceptable product (70).

\subsection{Topical administration}

As noted by Majuru and Oyewumi (70) the feasibility of applying nanoparticles in topical/cosmetic preparations has been a subject of several commentaries. In any case, this dosage form utilizes the advantages of nanoparticles such as (a) protection of labile compounds; (b) controlled release of incorporated drugs; (c) ability of solid lipid nanoparticles to act as occlusive to increase the water content of the skin; and (d) ability of nanoparticles to serve as physical barriers on the skin for blocking UV light and, as such, for use in sunscreen formulations.

\section{Conclusions}

Drug Delivery scientists are searching for the ideal nanovehicle for the ideal nanodrug delivery system; one that would dramatically reduce drug dosage, such that, there is improvement in the absorption of the drug, so that the patient can take a smaller dose, and yet have the same benefit, Deliver the drug to the right place in the living system, Increase the local concentration of the drug at the desired site and limit or eliminate side effects. As it stands today, the scope of this emerging field seems to be limitless. However, considerable technological and financial obstacles still need to be properly addressed by both the private sector and governments before nanotechnology's full promise can be realized. Ranking highest among the challenges is the need to develop and perfect reliable 
techniques to produce nanoscale particles that does not just have the desirable particle sizes, but also minimal structural defects and acceptable purity levels. This is because these attributes can drastically alter the anticipated behavior of the nanoscale particles. Moving today's promising nanotechnology-related developments from laboratory- and pilot-scale demonstrations to full-scale commercialization is still a big challenge and nanotechnology scientists must gear up to these challenges. Nanotechnology, deals with the design, characterization, production and application of structures, devices and systems by controlling shape and size at the nanometer scale. Two principal factors cause the properties of nanomaterials to differ significantly from other materials: increased relative surface area, and quantum effects. These factors can change or enhance properties such as reactivity, strength, electrical characteristics as well as most of the biomedical properties. Nanotechnology in biomedical sciences is expected to create innovations and play a vital role, not only in drug delivery and gene therapy, but also in molecular imaging, biomarkers and biosensors. Today the application of nanotechnology in drug delivery is widely expected to change the landscape of pharmaceutical and biotechnology industries for the foreseeable future. Target-specific drug therapy and methods for early diagnosis of pathologies are the priority research areas where nanotechnology would play a prominent role. Using nanotechnology, it may be possible to achieve (1) improved delivery of poorly water-soluble drugs; (2) targeted delivery of drugs in a cell- or tissuespecific manner; (3) transcytosis of drugs across tight epithelial and endothelial barriers; (4) delivery of large macromolecule drugs to intracellular sites of action; (5) co-delivery of two or more drugs or therapeutic modality for combination therapy; (6) visualization of sites of drug delivery by combining therapeutic agents with imaging modalities; and (7) real-time read on the in vivo efficacy of a therapeutic agent. For example, with more than 10 million new cases every year, cancer has become one of the most devastating diseases worldwide, yet, the most common cancer treatments are limited to chemotherapy, radiation, and surgery. Although conventional treatment options such as chemotherapy and radiation have experienced many advances over the past decades, cancer therapy is still far from optimal. Frequent challenges encountered by the current cancer therapies include nonspecific systemic distribution of antitumor agents, inadequate drug concentrations reaching the tumor, and the limited ability to monitor therapeutic responses. Poor drug delivery to the target site leads to significant complications, such as multidrug resistance, here nanodrug delivery holds great promise. A large number of nanocarriers have been designed for delivery of peptides via liposomes, noisome, polymeric nanoparticles, solid lipid nanoparticles etc. Polymeric based nanoparticles have taken much attention for safe and effective delivery of proteins. Nanoparticles prepared, particularly in the size range from $10 \mathrm{~nm}$ to $100 \mathrm{~nm}$, are considered optimal for cancer therapeutics. Thus multifunctional nanoparticles combining different functionalities like targeting, imaging and therapy into one system can be used for effective cancer treatment. Multifunctional nanoparticles hold great promise for the future of cancer treatment because they can detect the early onset of cancer in each individual patient and deliver suitable therapeutic agents to enhance therapeutic efficacy. The combination of tumor- 
targeted imaging and therapy in an all-in-one system provides a useful multimodal approach in the battle against debilitating health conditions like cancer. Despite the promise of many of the early nanotechnology-related breakthroughs, the ability to develop cost-effective, commercially and technically viable applications for these laboratory wonders will ultimately be predicated on the research community's ability to bridge the gap-some might say chasm-between the science involved and engineering required, particularly during scale up.

\section{Author details}

Martins Ochubiojo Emeje

Centre for Nanomedicine and Biophysical Drug Delivery,

National Institute for Pharmaceutical Research and Development,

Nigeria

Ifeoma Chinwude Obidike

National Institute for Pharmaceutical Research and Development,

Nigeria

Ekaete Ibanga Akpabio

University of Uyo, Akwa-Ibom State,

Nigeria

Sabinus Ifianyi Ofoefule

University of Nigeria, Nsukka,

Nigeria

\section{References}

[1] Maeda, H., Wu, J., Sawa, T., Matsumura, Y., and Hori, K. (2000) Tumor vascular permeability and the EPR effect in macromolecular therapeutics: a review. J. Controlled Release 65, 271-84.

[2] Palmer, T. N., Caride, V. J., Caldecourt, M. A., Twickler, J., and Abdullah, V. (1984) The mechanism of liposome accumulation in infarction. Biochim. Biophys. Acta 797, 363-8.

[3] Jaracz, S., Chen, J., Kuznetsova, L. V., and Ojima, I. (2005) Recent advances in tumortargeting anticancer drug conjugates. Bioorg. Med. Chem. 13, 5043-54.

[4] Torchilin, V. P. (2004) Targeted polymeric micelles for delivery of poorly soluble drugs. Cell Mol. Life Sci. 61, 2549-59.

[5] Gabizon, A., Shmeeda, H., Horowitz, A. T., and Zalipsky, S. (2004) Tumor cell targeting of liposome-entrapped drugs with phospholipid- anchored folic acid-PEG conjugates. AdV. Drug DeliVery ReV.56, 1177-92.

[6] Widera, A., Norouziyan, F., and Shen, W. C. (2003) Mechanisms of TfR-mediated transcytosis and sorting in epithelial cells and applications toward drug delivery. AdV. Drug DeliVery ReV.55, 1439-66. 
[7] Gupta, B., Levchenko, T. S., and Torchilin, V. P. (2005) Intracel- lular delivery of large molecules and small particles by cell- penetrating proteins and peptides. AdV. Drug DeliVery ReV.57, 637- 51.

[8] Lochmann, D., Jauk, E., and Zimmer, A. (2004) Drug delivery of oligonucleotides by peptides. Eur. J. Pharm. Biopharm. 58, 237- 51.

[9] Torchilin, V. P. (2005) Lipid-core micelles for targeted drug delivery. Curr. Drug DeliVery 2, 319-27.

[10] Torchilin, V. P. (2005) Recent advances with liposomes as pharmaceutical carriers. Nat. ReV. Drug DiscoVery 4, 145-60.

[11] Maheshwari, A., Mahato, R. I., McGregor, J., Han, S., Samlowski, W. E., Park, J. S., and Kim, S. W. (2000) Soluble biodegradable polymer-based cytokine gene delivery for cancer treatment. Mol. Ther. 2, 121-30.

[12] Tachibana, R., Harashima, H., Shono, M., Azumano, M., Niwa, M., Futaki, S., and Kiwada, H. (1998) Intracellular Regulation of Macromolecules Using pH-Sensitive Liposomes and Nuclear

[13] Lo- calization Signal: Qualitative and Quantitative Evaluation of Intra- cellular Trafficking. Biochem. Biophys. Res. Commun. 251, 538- 544.

[14] Torchilin, V. P., Rammohan, R., Weissig, V., and Levchenko, T. S. (2001) TAT peptide on the surface of liposomes affords their efficient intracellular delivery even at low temperature and in the presence of metabolic inhibitors. Proc. Natl. Acad Sci. U.S.A. 98, 8786-91.

[15] Wattiaux, R., Laurent, N., Wattiaux-De Coninck, S., and Jadot, M. (2000) Endosomes, lysosomes: their implication in gene transfer. AdV. Drug DeliVery ReV.41, 201208.

[16] Caron, N. J., Torrente, Y., Camirand, G., Bujold, M., Chapdelaine, P., Leriche, K., Bresolin, N., and Tremblay, J. P. (2001) Intracellular delivery of a Tat-eGFP fusion protein into muscle cells. Mol. Ther. 3, 310-8.

[17] Vives, E., Brodin, P., and Lebleu, B. (1997) A truncated HIV-1 Tat protein basic domain rapidly translocates through the plasma membrane and accumulates in the cell nucleus. J. Biol. Chem. 272, 16010-7.

[18] Fawell, S., Seery, J., Daikh, Y., Moore, C., Chen, L. L., Pepinsky, B., and Barsoum, J. (1994) Tat-mediated delivery of heterologous proteins into cells. Proc. Natl. Acad. Sci. U.S.A. 91, 664-8.

[19] Rudolph, C., Plank, C., Lausier, J., Schillinger, U., Muller, R. H., and Rosenecker, J. (2003) Oligomers of the arginine-rich motif of the HIV-1 TAT protein are capable of transferring plasmid DNA into cells. J. Biol. Chem. 278, 11411-8.

[20] Santra, S., Yang, H., Holloway, P. H., Stanley, J. T., and Mericle, R. A. (2005) Synthesis of water-dispersible fluorescent, radio-opaque, and paramagnetic CdS: $\mathrm{Mn} / \mathrm{ZnS}$ quantum dots: a multifunctional probe for bioimaging. J. Am. Chem. Soc. 127, 1656-7. 
[21] Schwarze, S. R., Ho, A., Vocero-Akbani, A., and Dowdy, S. F. (1999) In vivo protein transduction: delivery of a biologically active protein into the mouse. Science 285, 156972.

[22] Torchilin, V. P., Levchenko, T. S., Rammohan, R., Volodina, N., PapahadjopoulosSternberg, B., and D'Souza, G. G. (2003) Cell transfection in vitro and in vivo with nontoxic TAT peptide- liposome-DNA complexes. Proc. Natl. Acad. Sci. U.S.A. 100, 1972- 7 .

[23] Zhao, M., Kircher, M. F., Josephson, L., and Weissleder, R. (2002) Differential conjugation of tat peptide to superparamagnetic nano- particles and its effect on cellular uptake. Bioconjugate Chem. 13, 840-4.

[24] Mai, J. C., Shen, H., Watkins, S. C., Cheng, T., and Robbins, P. D. (2002) Efficiency of protein transduction is cell type-dependent and is enhanced by dextran sulfate. J. Biol. Chem. 277, 30208-18.

[25] Vives, E., Richard, J. P., Rispal, C., and Lebleu, B. (2003) TAT peptide internalization: seeking the mechanism of entry. Curr. Protein Pept. Sci. 4, 125-32.

[26] Snyder, E. L., and Dowdy, S. F. (2004) Cell penetrating peptides in drug delivery. Pharm. Res. 21, 389-93.

[27] Wadia, J. S., Stan, R. V., and Dowdy, S. F. (2004) Transducible TAT-HA fusogenic peptide enhances escape of TAT-fusion proteins after lipid raft macropinocytosis. Nat. Med. 10, 310-5.

[28] Sawant, R. M. Hurley, J. P. Salmaso, S. Kale, A. Tolcheva, E. Levchenko, T. S. and Torchilin V. P. (2006). "SMART" Drug Delivery Systems: Double-Targeted pH-Responsive Pharmaceutical Nanocarriers. Bioconjugate Chem. 17, No. 4, 943949

[29] Chu, L. Y., Liang, Y. J., Chen, W. M., Ju, X. J.,\&Wang, H. D. (2004). Preparation of glucose-sensitive microcapsules with a porous membrane and functional gates. Colloids Surf. B: Biointerfaces, 37, 9-14.

[30] Kim, J. J., \& Park, K. (2001). Modulated insulin delivery from glucose-sensitive hydrogel dosage forms. J. Control. Release, 77, 39-47.

[31] Lee, E. S., Shin, H. J., Na, K., \& Bae, Y. H. (2003). Poly(L-histidine)-PEG block copolymer micelles and $\mathrm{pH}$-induced destabilization. J. Control. Release, 90, 363-74.

[32] Lee, E. S., Na, K., \& Bae, Y. H. (2005a).Doxorubicin loadedpH-sensitive polymeric micelles for reversal of resistant MCF-7 tumor. J. Control. Release, 103, 405-18.

[33] Hruby, M., Konak, C., \& Ulbrich, K. (2005). Polymeric micellar pH-sensitive drug delivery system for doxorubicin. J. Control. Release, 103, 137-48.

[34] Ringsdorf, H. (1975). Structure and properties of pharmacologically active polymers. J. Polym. Sci. Polym. Sympo., 51, 135-153.

[35] Duncan, R. (2006). Polymer conjugates as anticancer nanomedicines. Nat. Rev. Cancer, 6, 688-701. 
[36] Duncan, R.; Ringsdorf, H.; Satchi-Fainaro, R., Polymer therapeutics: Polymers as drugs, drug and protein conjugates and gene delivery systems: Past, present and future opportunities. Advances in Polymer Science 2006, 192, (1), 1-8.

[37] Ringsdorf, H., Structure and Properties of Pharmacologically Active Polymers. Journal of Polymer Science, Polymer Symposia 1975, (51), 135-153.

[38] Harris, J. M.; Chess, R. B., Effect of pegylation on pharmaceuticals. Nature Reviews Drug Discovery 2003, 2, (3), 214-21.

[39] Veronese, F. M.; Pasut, G., PEGylation, successful approach to drug delivery. Nature Reviews Drug Discovery 2005, 10, (21), 1451-8.

[40] Parveen, S.; Sahoo, S. K., Nanomedicine: Clinical applications of polyethylene glycol conjugated proteins and drugs. Clinical Pharmacokinetics 2006, 45, (10), 965-988.

[41] Graham, M. L., Pegaspargase:Areview of clinical studies. Advanced Drug Delivery Reviews 2003, 55, (10), 1293-1302.

[42] Lee, S., Youn, Y. S., Lee, S. H., Byun, Y., \& Lee, K. C. (2006). PEGylated glucagon-like peptide-1 displays preserved effects on insulin release in isolated pancreatic islets and improved biological activity in db/db mice. Diabetologia, 49, 1608-11.

[43] Shimoboji, T., Larenas, E., Fowler, T., Kulkarni, S., Hoffman, A. S., \& Stayton, P. S. (2002). Photoresponsive polymer-enzyme switches. Proc. Natl. Acad. Sci. U S A, 99, 16592-6.

[44] Shimoboji, T., Larenas, E., Fowler, T., Hoffman, A. S., \& Stayton, P. S. (2003). Temperature-induced switching of enzyme activity with smart polymer-enzyme conjugates. Bioconjug. Chem., 14, 517-25.

[45] Lee, E. S., Na, K., \& Bae, Y. H. (2005b). Super pH-sensitive multifunctional polymeric micelle. Nano. Lett., 5, 325-9.

[46] Torchilin, V. P. (2006). Multifunctional nanocarriers. Adv. Drug Deliv. Rev., 58, 1532-55.

[47] Lukyanov, A. N., Elbayoumi, T. A., Chakilam, A. R., \& Torchilin, V. P. (2004). Tumortargeted liposomes: doxorubicin-loaded long-circulating liposomes modified with anticancer antibody. J. Control. Release, 100, 135-44.

[48] Craighead, H. (2006). Future lab-on-a-chip technologies for interrogating individual molecules. Nature, 442, 387-93.

[49] Demello, A. J. (2006). Control and detection of chemical reactions in microfluidic systems. Nature, 442, 394-402.

[50] El-Ali, J., Sorger, P. K., \& Jensen, K. F. (2006). Cells on chips. Nature, 442, 403-11.

[51] Janasek, D., Franzke, J., \& Manz, A. (2006). Scaling and the design of miniaturized chemical-analysis systems. Nature, 442, 374-80.

[52] Psaltis, D., Quake, S. R., \& Yang, C. (2006). Developing optofluidic technology through the fusion of microfluidics and optics. Nature, 442, 381-6.

[53] Whitesides, G. M. (2006). The origins and the future of microfluidics. Nature, 442, 36873.

[54] Yager, P., Edwards, T., Fu, E., Helton, K., Nelson, K., Tam, M. R., \&Weigl, B. H. (2006). Microfluidic diagnostic technologies for global public health. Nature, 442, 412-8. 
[55] Li, Y., Ho Duc, H. L., Tyler, B., Williams, T., Tupper, M., Langer, R., Brem, H., \& Cima, M. J. (2005). In vivo delivery of BCNU from a MEMS device to a tumor model. J. Control. Release, 106, 138-45.

[56] Maloney, J. M., Uhland, S. A., Polito, B. F., Sheppard, N. F., Jr., Pelta, C. M., \& Santini, J. T., Jr. (2005). Electrothermally activated microchips for implantable drug delivery and biosensing. J. Control. Release, 109, 244-55.

[57] Tao, S. L., \& Desai, T. A. (2005). Micromachined devices: the impact of controlled geometry from cell-targeting to bioavailability. J. Control. Release, 109, 127-38.

[58] Richards Grayson, A. C., Scheidt Shawgo, R., Li, Y., \& Cima, M. J. (2004). Electronic MEMS for triggered delivery. Adv. Drug Deliv. Rev., 56, 173-84.

[59] Hirsch, L. R., Gobin, A.M., Lowery, A. R., Tam, F., Drezek, R. A., Halas, N. J., \& West, J. L. (2006). Metal nanoshells. Ann. Biomed. Eng., 34, 15-22.

[60] Corot, C., Robert, P., Idee, J. M., \& Port, M. (2006). Recent advances in iron oxide nanocrystal technology for medical imaging. Adv. Drug Deliv. Rev., 58,1471-504.

[61] Mozafari M R and Sahin N O, Manufacturing methods and mechanism of formation of lipid vesicles. In: Nanoliposomes: From Fundamentals to Recent Developments. MozafariMR\& Mortazavi S M (Eds.), Trafford Publishing Ltd, Oxford, UK, pp 39-48, 2005

[62] Visser C C, Stevanovic S, Voorwinden L H, Bloois L V, Gaillard P J, Danhof M, Crommelin D J A and Boer A G, (2005).Targeting liposomes with protein drugs to the blood-brain barrier in vitro, European Journal of Pharmaceutical Sciences, 25, 299-305

[63] Lopez-Pinto J M, Gonzalez-Rodriguez M L and Rabasco A M, (2005). Effect of cholesterol and ethanol on dermal delivery from DPPC liposomes, International Journal of Pharmaceutics, 298, 1-12.

[64] Ozden M Y and Hasirci V N, (1991). Preparation and characterization of polymer coated small unilamellar vesicles, Biochimica et Biophysica Acta (BBA) - General Subjects, 1075, 102-108.

[65] Ito A, Hibino E, Honda H, Hata K, Kagami H, Ueda M and Kobayashi T, (2004). A new methodology of mesenchymal stem cell expansion using magnetic nanoparticles, Biochemical Engineering Journal, 20, 119-125.

[66] Kunisawa J, Masuda T, Katayama K, Yoshikawa T, Tsutsumi Y, Akashi M, Mayumi T and Nakagawa S, (2005). Fusogenic liposome delivers encapsulated nanoparticles for cytosolic controlled gene release, Journal of Controlled Release, 105, 344-353.

[67] Foco A, Gasperlin M and Kristl J, (2005). Investigation of liposomes as carriers of sodium ascorbyl phosphate for cutaneous photoprotection, International Journal of Pharmaceutics, 291, 21-29.

[68] Sinico C, Manconi M, Peppi M, Lai F, Valenti D and Fadda A M, (2005). Liposomes as carriers for dermal delivery of tretinoin: in vitro evaluation of drug permeation and vesicle-skin interaction, Journal of Controlled Release, 103, 123-136. 
[69] Arcon I, Kodre A, Abra R M, Huang A, Vallner J J and Lasic D D, (2004). study of liposome- encapsulated cisplatin, Colloids and Surfaces B: Biointerfaces, 33, 199204.

[70] Shingai Majuru and Moses O. Oyewumi. Nanotechnology in Drug Development and Life Cycle Management. M.M. de Villiers et al. (eds.), Nanotechnology in Drug Delivery, (2009). Chapter 20, Pp. 597 - 619

[71] T. Jung,W. Kamm, A. Breitenbach, E. Kaiserling, J.X. Xiao, T. Kissel, (2000). Biodegradable nanoparticles for oral delivery of peptides: is there a role for polymers to affect mucosal uptake? Eur. J. Pharm. Biopharm. 50 147-160.

[72] C. Pinto Reis, R.J. Neufeld, A.J. Ribeiro, F. Veiga, (2006). Nanoencapsulation I. Methods for preparation of drug-loaded polymeric nanoparticles, Nanomedicine 2 8-21.

[73] L. Illum, (2007). Nanoparticulate systems for nasal delivery of drugs: a real improvement over simple systems? J. Pharm. Sci. 96 473-483.

[74] Geresh, S., Gdalevsky, G.Y., Gilboa, I., Voorspoels, J., Remon, J.P., Kost, J (2004). Bioadhesive grafted starch copolymers as platforms for peroral drug delivery: a study of theophylline release. Journal of controlled release 94(2-3): 391-399.

[75] Levina, M., Rajabi-Siahboomi,A.R. (2004). The influence of excipients on drug release from hydroxypropylmethyl cellulose matrices. Journal of pharmaceutical sciences 93(11): 2746-2754.

[76] Yamini, K., Chalapathi, V., Lakshmi Narasimha Reddy, N., Lokesh, K.V., Praveen Kumar Reddy, S., Gopal,V. (2011). Formulation of diclofenac sodium tablets using tapioca starch powder- A promising binder. Journal of applied pharmaceutical sciences 1(3):125-127)

[77] Malafaya. B, P., Stappers, F., Reis, R.L. (2006). Starch-based microspheres produced by emulsion crosslinking with a potential media dependent responsive behavior to be used as drug delivery carriers. Journal of material science: Materials in medicine 17: 371-377.

[78] Heller J., P.S.H., Roskos K.V. (1990). Development of enzymatically degradable protective coatings for use in triggered drug delivery systems: derivatized starch hydrogels. Biomaterials 11(5) : 345-350

[79] Wu, C., Zhongyan, W., Zhi, Z., Jang, T., Zhang, J., Wang, S (2011). Development of biodegradable porous starch foam for improving oral delivery of poorly water soluble drugs. International journal of pharmaceutics 403: 162-169.

[80] Santander-Ortega, M.J., Stauner, T., Loretz, B., Ortega-Vinuesa, J.L., Bastos-González, D., Wenz, G., Schaefer U.F., Lehr, C.M. (2010). Nanoparticles made from novel starch derivatives for transdermal drug delivery. Journal of controlled release 141:85-92.

[81] Mahkam, M. (2010). Modified Chitosan Cross-linked Starch Polymers for Oral Insulin Delivery. Journal of Bioactive and Compatible polymers 25(4): 406-418

[82] Jain, A.K., Khar, R.K., Ahmed, F.J., Diwan. P.V (2008). Effective insulin delivery using starch nanoparticles as a potential trans-nasal mucoadhesive carrier.European Journal of Pharmaceutics and Biopharmaceutics 69 (2):426-435 
[83] Simi, C.K., Abraham, T.E. (2007). Hydrophobic grafted and cross-linked starch nanoparticles for drug delivery. Bioprocess and biosystems engineering 30(3): 173-180

[84] Cole, A.J., David, A.E., Wang, J., Galbian, C., Yang, V.C. (2011). Magnetic brain tumor targeting and biodistribution of long-circulating PEG-modified, cross-linked starchcoated iron oxide nanoparticles. Biomaterials 32(26): 6291-6301

[85] Sabnis, S., Block, L (2000). Chitosan as an enabling excipient for drug delivery systems: 1.Molecular Modifications. International journal of biologicalmacromolecules 27(3): 181186

[86] Park, J.H., Saravanakuma, G., Kwangmeyung, K., Kwon, I. (2010) Targeted delivery of low molecular drugs using chitosan and its derivatives. Advanced drug delivery reviews 62(1): 28-41

[87] Thacharodi, D., Panduranga Rao, K (1996) Collagen-Chitosan composite membranes controlled transdermal delivery of nifedipine and propranolol hydrochloride. International journal of pharmaceutics 134:239-241.

[88] Thacharodi, D., Panduranga Rao, K. (1995) Development and in-vitro evaluation of chitosan-based transdermal drug delivery systems for the controlled delivery of propranolol hydrochloride. Biomaterials 16: 145-148

[89] Dev, A., Binulal , N.S., Anitha, A., Nair, S.V., Furuike,T., Tamura, H., Jayakumar, R., (2010) Preparation of poly (lactic acid)/chitosan nanoparticles for anti-HIV drug delivery applications. Carbohydrate polymers 80: 833-838

[90] Menon, D., Thomas, R.T., Narayanan, S., Maya, S., Jayakumar, R., Hussain, F., Lakshmanana, V., Nair, S.V. (2011) A novel chitosan/polyoxometalate nano-complex for anti-cancer applications. Carbohydrate polymers 84:887-893

[91] Luo, Q., Zhao, J., Zhang, X., Pan, W (2011) Nanostructured lipid carrier (NLC) coated with chitosan oligosaccharides and its potential use in ocular drug delivery system. International journal of pharmaceutics 403(1-2): 185-191

[92] Bajpai, A.K., Choubey, J. (2005) Release study of sulphamethoxazole controlled by swelling of gelatin nanoparticles and drug-biopolymer interaction. Journal of macromolecular science 42:253-275.

[93] Das, P.R., Nanda, R.M., Behara, A., Nayak, P.R. (2011) Gelatin blended with nanoparticle cloisite30B (MMT) for control drug delivery of anticancer drug paclitaxel International research journal of biochemistry and bioinformatics 1(2):35-42.

[94] Coester, C., Kreuter, J., von Briesen, H., Langer. K. (2000) Preparation of avidin-labelled gelatin nanoparticles as carriers for biotinylated peptide nucleic acid (PNA). International journal of pharmaceutics 196:147-149

[95] Zwiorek, K., Kloeckner, J., Wagner, K,. Coeste, C. (2004) Gelatin nanoparticles as a new and simple gene delivery system. Journal of pharmacy and pharmaceutical sciences $7(4): 22-28$

[96] Xu, X., Capito, R.M.,Spector, M. (2008) Delivery of plasmid IGF-1 to chondrocytes via cationizedgelatin nanoparticles. Journal of Biomedical material research 84(1): 73-83 
[97] K.K. Jain, Nanopharmaceuticals Chapter 4 In: The Handbook of Nanomedicine, 2008 Humana Press, Totowa, NJ pp 119 - 160

[98] Kipp, J.E. (2004) The role of solid nanoparticle technology in the parenteral delivery of poorly water-soluble drugs. Int. J. Pharm. 284, 109-122

[99] A. K. Bajpai, Jyoti Choubey. (2006). Design of gelatin nanoparticles as swelling controlled delivery system for chloroquine phosphate. J Mater Sci: Mater Med 17: 345358

[100] Daniel Honig, Jason DeRouchey, Ralf Jungmann, Christian Koch, Christian Plank and Joachim O. Radler. Biophysical Characterization of Copolymer-Protected Gene Vectors. Biomacromolecules, 2010, 11 (7), pp 1802-1809

[101] Luigi Battaglia, Michele Trotta, Marina Gallarate, M. Eugenia Carlotti, Gian Paolo Zara,\& Alessandro Bargon. Solid lipid nanoparticles formed by solvent-in-water emulsion-diffusion technique: Development and influence on insulin stability. Journal of Microencapsulation, November 2007; 24(7): 672-684

[102] Bargoni A, Cavalli R, Caputo O, Fundaro A, Gasco MR, Zara GP. 1998. Solid lipid nanoparticles in lymph and plasma after duodenal administration to rats. Pharmaceutical Research 15:745-750.

[103] Trotta M, Debernardi F, Caputo O. 2003. Preparation of solid lipid nanoparticles by a solvent emulsification-diffusion technique. International Journal of Pharmaceutics 257:153-160.

[104] Trotta M, Cavalli R, Carlotti ME, Battaglia L, Debernardi F. 2005. Solid lipid microparticles carrying insulin formed by solvent-in-water emulsion-diffusion technique. International Journal of Pharmaceutics 288:281-288.

[105] Müller RH. Lipid nanoparticles: recent advances. Adv Drug Deliv Rev 2007;59:522-30.

[106] Joshi M, Müller RH. Lipid nanoparticles for parenteral delivery of actives. Eur J Pharm Biopharm 2009;71:161-72.

[107] Müller RH, Radtke M, Wissing SA. Nanostructured lipid matrices for improved microencapsulation of drugs. Int J Pharm 2002;242:121-8.

[108] Müller RH. Preparation, characterization and physico-chemical properties of solid lipid nanoparticles (SLN) and nanostructured lipid carriers (NLC): their benefits as colloidal drug carrier systems. Pharmazie 2006;61:375-86.

[109] Müller RH, Radtke M, Wissing SA. Solid lipid nanoparticles (SLN) and nanostructured lipid carriers (NLC) in cosmetic and dermatological preparations. Adv Drug Deliv Rev 2002;54:S131-55.

[110] Doktorovova S, Souto EB. Nanostructured lipid carriers-based hydrogel formulations for drug delivery: A comprehensive review. Expert Opin Drug Deliv 2009;6:165-76.

[111] Souto EB, Müller RH. Lipid nanoparticles: effect on bioavailability and pharmacokinetic changes. Handb Exp Pharmacol 2010;115-41.

[112] Souto EB. A special issue on lipid-based delivery systems (liposomes, lipid nanoparticles, lipid matrices and medicines). J Biomed Nanotechnol 2009;5:315-6. 
[113] Martins Emeje; John-Africa, Lucy; Yetunde Isimi; Olobayo Kunle and Sabinus Ofoefule (2012). Eudraginated - polymer blends: a potential oral controlled drug delivery system for theophylline. Acta Pharmaceutica 62: 71 - 82.

[114] Lu B, Zhang JQ, Yang H. (2003). Lung-targeting microspheres of carboplatin. Int J Pharm, 265:1-11. 